\title{
Degradation of Organic UV filters in Chlorinated Seawater Swimming Pools: Transformation Pathways and Bromoform Formation
}

\author{
Tarek Manasfi ${ }^{\mathrm{a}}$, Bruno Coulomb ${ }^{\mathrm{a}}$, Sylvain Ravier ${ }^{\mathrm{a}}$, Jean-Luc Boudenne $^{\mathrm{a},{ }^{*}}$ \\ ${ }^{a}$ Aix Marseille Univ, CNRS, LCE, Marseille, France \\ ${ }^{*}$ Corresponding author. Address: Aix-Marseille University-CNRS, Faculty of Sciences, \\ Department of Chemistry, Laboratory of Environmental Chemistry, 3 Place Victor Hugo - Case \\ 29, CS80249, F-13331 Marseille Cedex 03; Phone: (+33) (0)413551031; Fax: $(+33)$ \\ (0)413551060; e-mail: jean-luc.boudenne@univ-amu.fr
}

\begin{abstract}
Organic ultraviolet (UV) filters are used in sunscreens and other personal-care products to protect against harmful effects of exposure to UV solar radiation. Little is known about the fate of UV filters in seawater swimming pools disinfected with chlorine. The present study investigated the occurrence and fate of five commonly used organic UV filters, namely dioxybenzone, oxybenzone, avobenzone, 2-ethylhexyl-4-methoxycinnamate, and octocrylene, in chlorinated seawater swimming pools. Pool samples were collected to monitor the variation of UV filter concentrations during pool opening hours. Furthermore, laboratory-controlled chlorination experiments were conducted in seawater spiked with UV filters to investigate the reactivity of UV filters. Extracts of chlorination reaction samples were analyzed using high-resolution mass spectrometry and electron-capture detection to identify the potentially formed byproducts. In the collected pool samples, all the UV filters except dioxybenzone were detected. Chlorination reactions showed that only octocrylene was stable in chlorinated seawater. The four reactive UV filters generated brominated transformation products and disinfection byproducts. This formation of brominated products resulted from reactions between the reactive UV filters and bromine, which is formed rapidly when chlorine is added to seawater. Based on the identified byproducts, the transformation pathways of the reactive UV filters were proposed for the first time. Bromoform was generated by all the reactive UV filters at different yields. Bromal hydrate was also detected as one of the byproducts generated by oxybenzone and dioxybenzone.
\end{abstract}


Keywords: UV filter; swimming pool; transformation pathway; brominated disinfection byproduct; bromoform

\section{INTRODUCTION}

Ultraviolet (UV) filters are the active ingredients in sunscreens and are added to many personalcare products (PCPs) such as cosmetics, lipsticks, and hair sprays. During the last decades, there have been an increasing production and use of UV filters due to rising concerns about the harmful health effects associated with exposure to UV solar radiation in humans. UV filtering compounds are either mineral or organic. Organic UV filters protect from UV radiation by absorbing light and converting it into a small amount of heat through their conjugated chemical structures. Mineral filters, such as titanium dioxide and zinc oxide, act by scattering and reflecting UV radiation. ${ }^{1}$ Since a single UV filter only blocks a specific wavelength range of radiation, multiple UV filters are incorporated in a sunscreen formulation to offer protection against a wide range of UV radiation. In a sunscreen, UV filters can account for more than $10 \%$ of the product mass. ${ }^{2}$ UV filters have been detected in sediments, soils, and in natural, tap and swimming pool waters. ${ }^{3}$ Many people take part in activities such as swimming, bathing and water sports while wearing sunscreens. UV filters in some sunscreens are readily washed off after a single immersion in water, even those labeled 'water-resistant' or 'waterproof'. ${ }^{4}$ Some studies showed that sunscreens claimed to be 'water-resistant' only possess between 10 and $30 \%$ waterresistance retention ${ }^{5}$, and thus, are partially washed off after a single immersion in the pool. ${ }^{6} \mathrm{UV}$ filters have been detected in swimming pool waters and spas with concentrations ranging from the $n g \mathrm{~L}^{-1}$ to the $\mu \mathrm{g} \mathrm{L}^{-1}$ levels. ${ }^{5,7-11}$ The release of recreational waters such as those of swimming pools into the environment represents one of the main input routes of UV filters into water bodies (e.g. rivers, lakes, sea). ${ }^{12}$ UV filters such as 2-ethylhexyl methoxycinnamate, also known as octylmethoxy cinnamate (OMC), octrocrylene (OC), and oxybenzone (OXY) have been detected in fish in Swiss lakes ${ }^{13}$ and in marine mammals in Brazilian coastal areas. ${ }^{14}$ Concerns about the bioaccumulation and persistence of UV filters in the environment have been raised because of an increasing number of experimental studies indicating that several UV filters might have endocrine disruptive effects. ${ }^{15-20}$ Furthermore, Nakajima et al. showed that the chlorination of water containing $\mathrm{OMC}$ increased the mutagenic activity of water. ${ }^{21}$ In consequence to these concerns, investigations about the occurrence and behavior of UV filters in the environment have 
increased in the last few years. ${ }^{22}$ Some studies investigated the fate of UV filters when exposed to chemical oxidants or light. ${ }^{1}$ The determination of the fate of UV filters and the identification of their transformation products is necessary for health risk assessment since byproducts with unknown toxicities could be formed following the transformation of UV filter in presence of oxidants such as chlorine. ${ }^{21,23}$ Chlorine is the most popular disinfectant in swimming pools. ${ }^{24}$ To date, there have been few investigations examining the fate of organic UV filters in the presence of chlorine in tap water and freshwater. ${ }^{12,21,25,26}$ Previous studies examined the reactivity of few UV filters with aqueous chlorine using laboratory-controlled experiments. Sakkas et al. studied the reactivity of octyl dimethyl- $p$-aminobenzoic acid (ODPABA) with chlorine and showed the formation of monochlorinated byproducts of ODPABA. ${ }^{26}$ Negreira et al. studied the reactivity of 2-ethylhexyl salicylate (ES) and ODPABA in the presence of excess chlorine. ES reacted at lower rates than ODPABA which was readily degraded upon chlorination. ${ }^{12}$ Duirk et al. investigated the kinetic rates of reactions of two benzophenone UV filters with aqueous chlorine. ${ }^{25}$ The two benzophenone UV filters were rapidly transformed, but their transformation pathways were not elucidated. Some commonly used UV filters such as AVO, OMC, and OC have received less attention compared to benzophenone UV filters and their reactivity in swimming pools remain largely unknown. Furthermore, available data regarding the reactivity of UV filters based on laboratory-controlled chlorination experiments have not been confronted with findings of field studies assessing the occurrence trends of the corresponding UV filters in chlorinated swimming pools. Besides, in swimming pools one of the main aspects relevant to chemical health is the formation of disinfection byproducts (DBPs), which have been linked to a range of adverse health effects. ${ }^{10,22}$ Organic UV filters have been detected in swimming pools, ${ }^{5,7,8,9,11}$ yet their contribution to the formation of disinfection byproducts (DBPs) is so far largely unknown. ${ }^{10}$ In seawater pools, questions regarding the fate of UV filters and their contribution to the formation of DBPs are of particular concern for several reasons. In chlorinated seawater pools, the presence of high concentrations of bromide (about $67 \mathrm{mg} \mathrm{L}^{-1}$ ) could result in higher reactivity of UV filters than in chlorinated freshwater pools. ${ }^{27}$ Chlorinated seawater can be found in some swimming pools and in centers of thalassotherapy where seawater properties are used for health and wellness purposes. ${ }^{28-30}$ The use of seawater in thalassotherapy centers has been developing in Europe since the early 1900s for presumed health benefits. ${ }^{29}$ Today, there are around 70 thalassotherapy centers along the French coasts. ${ }^{31}$ According to some estimates, 
French thalassotherapy centers welcome more than one million users annually. ${ }^{32}$ More generally, thalassotherapy can technically be found anywhere where there is a seacoast. ${ }^{31}$ Furthermore, the use of seawater in pools is not limited to thalassotherapy pools since recreational seawater pools can be found in water parks, hotels, resorts, and on cruise ships. ${ }^{33}$ Similar to freshwater pools, seawater pools should be disinfected to reduce risks of infections caused by pathogenic microorganisms present in water. ${ }^{34}$ When chlorine is added to seawater $(\mathrm{pH} \sim 8)$, it rapidly reacts with bromide ions $\left(\mathrm{Br}^{-}\right)$resulting in the formation of bromine most abundantly in the form of hypobromous acid $(\mathrm{HOBr})$ and hypobromite ions $\left(\mathrm{OBr}^{-}\right) .{ }^{35}$ Bromine reacts with organic compounds present in pool waters generating brominated byproducts. The reaction rate of bromine with phenol-like organic compounds was estimated to be about $10^{3}$-fold higher than with chlorine. ${ }^{36,37}$ The potential formation of brominated byproducts from organic compounds including organic UV filters in chlorinated seawater pools is a matter of concern for health risk considerations. Several studies have shown that brominated byproducts are considerably more toxic than their chlorinated analogues. ${ }^{38-40}$ Toxicological studies conducted on laboratory animals associated exposure to brominated byproducts with higher risks of colon cancer. ${ }^{41}$ In the present study, the occurrence and reactivity of five commonly used UV filters (Table 1) in chlorinated seawater swimming pools was investigated. The studied UV filters were oxybenzone (OXY), dioxybenzone (DIOXY), avobenzone (AVO), 2-ethylhexyl-4-methoxycinnamate (also known as octylmethoxy cinnamate, OMC), and octocrylene (OC). These UV filters were selected because previous surveys highlighted their frequent use in sunscreens. ${ }^{25,42,43}$ The aims of the study were to i) determine the occurrence and monitor the variation of the concentrations of UV filters in seawater swimming pools disinfected with chlorine as a function of pool opening hours, ii) investigate the reactivity of the UV filters in chlorinated seawater, and iii) identify the potentially formed halogenated transformation products and DBPs.

\section{EXPERIMENTAL SECTION}

Chemicals. Standards of OXY, DIOXY, AVO, OMC, OC and benzophenone-d10 were purchased from Sigma-Aldrich Fluka (purity > 98\%). 2,4,6-tribromo-3-methoxyphenol (TBMP) was purchased from Sigma-Aldrich (Saint-Quentin Fallavier, France). Salicylic acid (purity > 99\%) was purchased from Acros Organics (Geel, Belgium). Ammonium formate (UHPLC/MS 
grade) was purchased from Biosolve Chimie (Dieuze, France). Trihalomethane (THM) calibration mix containing chloroform $\left(100.3 \mathrm{mg} \mathrm{L}^{-1}\right)$, bromodichloromethane $\left(94.8 \mathrm{mg} \mathrm{L}^{-1}\right)$, dibromochloromethane (94.6 $\left.\mathrm{mg} \mathrm{L}^{-1}\right)$, and bromoform $\left(93.5 \mathrm{mg} \mathrm{L}^{-1}\right)$, was purchased from Supelco (Bellefonte, PA, USA) and tribromoacetaldehyde (97\%) was purchased from Aldrich (Dorset, United Kingdom). Standard solutions of UV filters were prepared with methanol (Ultra Chromasolv, purity $>99.9 \%$ ).

Table 1. CAS numbers, chemical structures, and Log $K_{\text {ow }}$ * values of the UV filters investigated

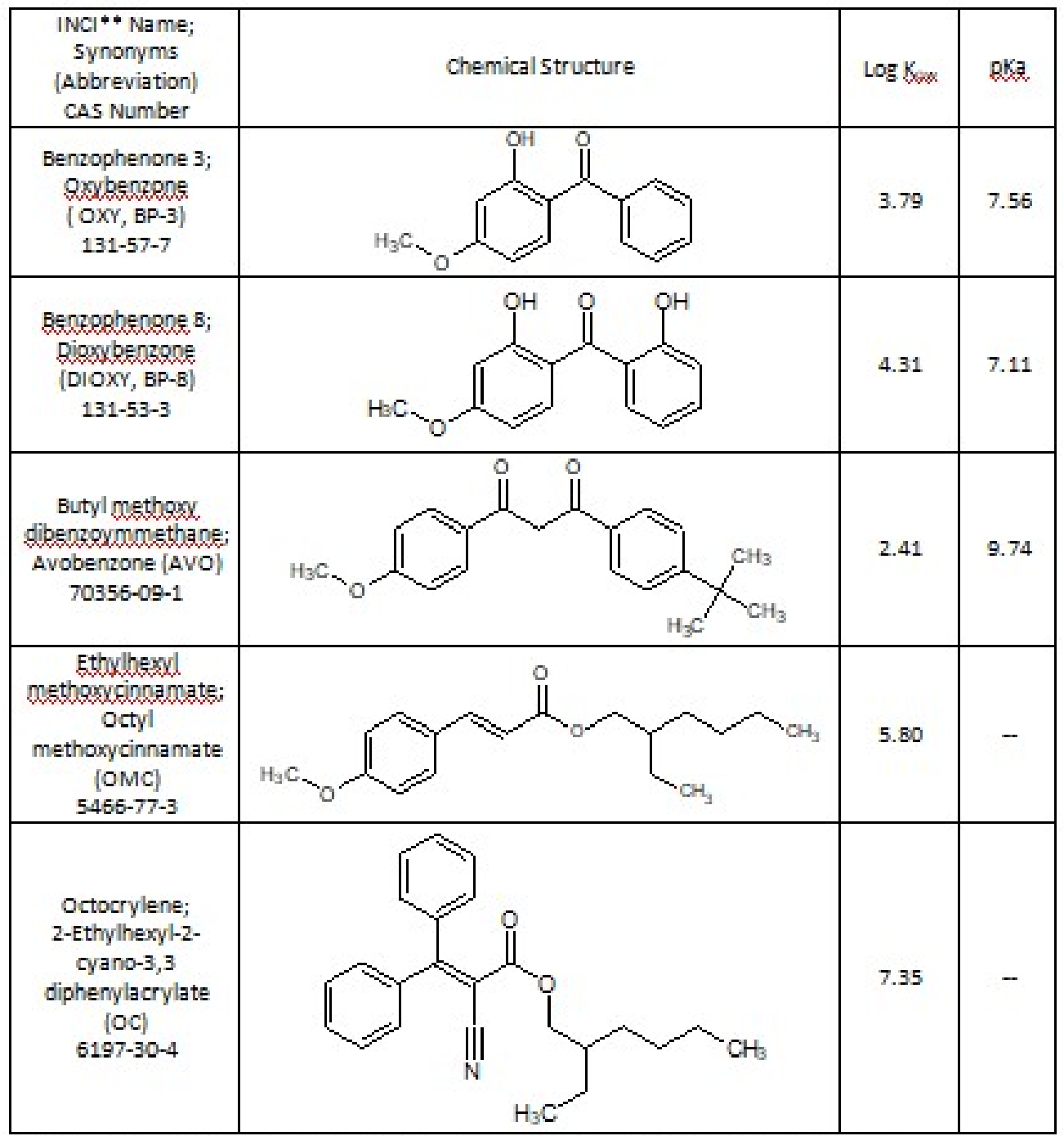

* Koy refers to the octanol-water partition coefficient; values adapted from [Santos et al., 2012); also known as LegP.

** INCI: International Nomenclature of Cosmetic Ingredients pKa values at $25{ }^{\circ} \mathrm{C}$ 
Stock solutions of chlorine were prepared by diluting a reagent grade commercial solution of sodium hypochlorite $(\mathrm{NaOCl}$, available chlorine 4.00 - 4.99\%, Sigma-Aldrich). Reconstituted seawater was prepared according to the ASTM International standard practice for the preparation of substitute ocean water (method D1141-98, 2013). Methyl tert-butyl ether (MTBE, Chromosolv, HPLC grade, Sigma-Aldrich, Germany) was used for extraction. An aqueous solution of L-ascorbic acid (reagent grade, Sigma, China) was prepared using ultrapure water (Millipore water system, resistivity $>18 \mathrm{M} \Omega \mathrm{cm}$ ) and was used for quenching. Glassware was washed with a chlorine solution and thoroughly cleaned prior to usage so that any contaminating organic matter could be eliminated. All experiments were performed at $25^{\circ} \mathrm{C}$.

Collection of swimming pool water samples. Samples were collected from two outdoor swimming pools located in the region of Southeastern France. One of the pools was for adults while the other was for children. Both pools were filled with seawater and were disinfected with chlorine. According to pool operators, the pools are drained and refilled by seawater pumped from the Mediterranean Sea on daily basis. Sampling was performed during pool opening hours starting from pool opening in the morning till closure in the evening with samples collected at $1-\mathrm{h}$ intervals. The first sample was collected upon filling the pools with filtered seawater before the entrance of users to the pools to confirm the absence of UV filters from the filling water. Water samples were collected in 1-L amber glass bottles. Ascorbic acid was added to quench chlorine and stop further chlorination reactions. Samples were stored at $4{ }^{\circ} \mathrm{C}$ away from sunlight and were extracted within $24 \mathrm{~h}$ after collection. To confirm that no contamination took place during the treatment of samples or during analysis with ultra-high-performance liquid chromatography coupled to tandem mass spectrometry (UHPLC-MS/MS), blank samples were prepared using ultrapure water (Milli-Q, Millipore system) and were treated similarly to the collected pool samples.

Physicochemical parameters, bromide concentration, free and combined chlorine in pool water samples. Physicochemical parameters including $\mathrm{pH}$, temperature, and conductivity were determined on-site using multi-electrode from WTW (SenTix 41-3 pH electrode and WTW Pt 4805/S7 electrode). Bromide concentrations were determined using an ICS-3000 Dionex ion chromatography system $\left(30 \mathrm{mM} \mathrm{NaOH}\right.$ eluent with a flow rate of $1.5 \mathrm{~mL} \mathrm{~min}^{-1}$ at $\left.30{ }^{\circ} \mathrm{C}\right)$. Free 
chlorine and combined chlorine were measured on-site by the colorimetric DPD method using a portable spectrophotometer (AQUALYTIC-AL 800, Germany).

Chlorination reactions of UV filters in reconstituted seawater. To investigate the fate of UV filters in chlorinated seawater swimming pools, chlorination experiments were conducted by adding excess chlorine to reconstituted seawater spiked with UV filters. The use of reconstituted seawater, which only contains minerals rather than organic compounds naturally present in seawater, enables the determination of the kinetics of disappearance of the UV filters and the formation of their transformation products without interferences from other organic compounds. In non-reconstituted seawater, even if filtration is performed, the presence of organic matter cannot be ruled out making uncertain the qualitative and quantitative attribution of the formed halogenated byproducts to UV filters exclusively. Chlorination experiments were carried out in 65-mL glass vials with PTFE-lined screw caps. Vials were filled with reconstituted seawater containing a UV filter at an initial concentration of $1 \mu \mathrm{M}$. All vials were filled without headspace so that any potentially formed volatile byproduct would not be lost. Vials were placed in water baths at $25^{\circ} \mathrm{C}\left( \pm 1{ }^{\circ} \mathrm{C}\right)$ away from sunlight to avoid any risk of photodegradation. Reactions were initiated by adding aliquots of the concentrated chlorine solution corresponding to the amount needed to obtain an initial chlorine concentration of 10,25 , and $100 \mu \mathrm{M}$. In these conditions, the molar ratios of UV filter/chlorine were 1:10, 1:25, and 1:100 (designated in the text as R10, R25 and R100, respectively). An additional ratio of 1:1000 was included for the UV filter OC. The different chlorination ratios were used to simulate realistic conditions in swimming pools where different chlorine concentrations could be used for disinfection. At different reaction times, ascorbic acid was added in excess to quench free chlorine. The first time-point ( $\mathrm{t}=0 \mathrm{~min}$ ) was obtained by adding ascorbic acid before the addition of chlorine. The $\mathrm{pH}$ was measured at each time point to verify that it remained constant during experiments. No $\mathrm{pH}$ variations higher than 0.1 unit was observed. Samples were analyzed using UHPLC-MS/MS to determine the remaining concentration of UV filters as a function of reaction time and to identify the potentially formed transformation products. Samples were also analyzed with gas chromatography coupled to an electron-capture detector (GC-ECD) and gas chromatography coupled to a mass spectrometer (GC-MS) to investigate the formation of volatile halogenated byproducts. To evaluate the relevance of chlorination reaction findings when the UV filters are exposed solar radiation (as in 
outdoor pools), chlorination experiments at ratio UV filter:chlorine 1:25 were conducted under solar irradiation produced by a solar simulator (Solsim, Luzchem Research, Ottawa, Ontario, Canada) with a $300 \mathrm{~W}$ ceramic xenon lamp power supply (XE300BF, Luzchem Research) as the light source. Photoexposure was carried out at 44,000 1x, which represents the annual average solar radiation in southern France. ${ }^{44}$

\section{Sample Treatment}

Chlorination reactions. The chlorinated seawater solutions of the UV filters were acidified (to $\mathrm{pH}=2$ ) using concentrated sulfuric acid. Liquid-liquid extraction (LLE) was then performed by applying MTBE $(5 \mathrm{~mL})$ to an aliquot $(50 \mathrm{~mL})$ of the sample. Sodium sulfate $(10 \mathrm{~g})$ was added and vials were vigorously shaken manually for $2 \mathrm{~min}$. The addition of sodium sulfate enhances the separation of the two liquid phases. ${ }^{36}$ The organic phases were recovered and added to chromatography vials for analyses (UHPLC-MS, GC-ECD, and GC-MS analyses).

Concentrations of UV filters in swimming pool samples. Pool samples were extracted using LLE with MTBE similarly to the procedure followed in the treatment of chlorination reaction samples. To further decrease the detection limits, the LLE extracts $(5 \mathrm{~mL})$ were concentrated to a final volume of $0.5 \mathrm{~mL}$ using a gentle stream of nitrogen at $50{ }^{\circ} \mathrm{C}$. Benzophenone-d10 was added as a surrogate.

\section{Analytical Procedures}

UHPLC-MS/MS Analysis. Extracts of field and laboratory samples were analyzed using UPLC system (Acquity, Waters) coupled to quadrupole/time-of-flight mass spectrometry (Q/ToF-MS) with electrospray ion (ESI) source (Synapt G2 HDM, Waters, MA, USA). Calibration curves were established for each UV filter by external standard approach using the reference standard. Benzophenone-d10 was used as surrogate. Calibration standards were prepared by spiking reconstituted seawater with UV filters and then performing the same procedure used for sample analysis (LLE-UHPLC-MS/MS). Quantitation of UV filters was performed by following the same procedure used to establish the calibration curves. The operating conditions used in UHPLC-MS/MS analyses are described below.

Separation of analytes were achieved using a CORTECS UPLC column (Waters Acquity C18 $2.1 \times 100 \mathrm{~mm}, 1.6 \mu \mathrm{M})$ at $40{ }^{\circ} \mathrm{C}$. The mobile phase consisted of A: water and B: methanol 
(ULC/MS grade, Bisolve). Both solvents A and B contained $5 \mathrm{mM}$ ammonium formate. Elution was performed at a flow rate of $0.4 \mathrm{ml} \mathrm{min}^{-1}$ with a gradient starting at $15 \%$ of $\mathrm{B}$ and increasing to reach $100 \%$ within 6 min and held for $1 \mathrm{~min}$. The sample injection volume was $5 \mu \mathrm{L}$. The ESI source contained two individual orthogonal sprays. One spray was for the column eluent while the other was for the internal standard (lockmass). During each chromatographic run, leucine enkephalin ( $2 \mathrm{mg} \mathrm{L}^{-1}, \mathrm{C}_{28} \mathrm{H}_{37} \mathrm{~N}_{5} \mathrm{O}_{7}$, MW 555.27, Waters Q-ToF product) was used for lock-mass correction to obtain accurate masses for each organic component eluting from the column. A solution of sodium formate (HCOONa, Waters Q-ToF product) was infused daily in the ESI source to calibrate the instrument. Optimum ESI conditions were found using a $2.5 \mathrm{kV}$ capillary voltage, $450{ }^{\circ} \mathrm{C}$ desolvation temperature, $120{ }^{\circ} \mathrm{C}$ source temperature, $20 \mathrm{~L} \mathrm{~h}^{-1}$ cone gas flow rate and $800 \mathrm{~L} \mathrm{~h}^{-1}$ desolvation gas flow rate. The optimum sample cone voltage for each analyte is described in Table S1. The ESI source has been optimized directly with the samples. These parameters allowed increasing the signal to noise ratio maintaining soft ionization technique. Data were collected from 50 to $600 \mathrm{Da}$ in the positive and negative ionization modes. The mass spectrometer was used in its resolution mode. Compounds responding in positive mode were detected as their protonated molecules $\left([\mathrm{M}+\mathrm{H}]^{+}\right)$or sodium adducts $\left([\mathrm{M}+\mathrm{Na}]^{+}\right)$or potassium adducts $\left([\mathrm{M}+\mathrm{K}]^{+}\right)$while compounds responding in the negative mode were detected as deprotonated molecules $\left([\mathrm{M}-\mathrm{H}]^{-}\right)$.

MS/MS transitions used for quantitation of the UV filters are described in Table S1.

Table Sl. UV Filter Retention time (RT) and MS/MS operating conditions

\begin{tabular}{|l|l|l|l|l|l|}
\hline Analyte & RT (min) & $\begin{array}{l}\text { Parent Ion } \\
{[\mathbf{M}+\mathbf{H}]^{+}}\end{array}$ & $\begin{array}{l}\text { Cone Voltage } \\
(\mathbf{V})\end{array}$ & $\begin{array}{l}\text { Fixed CE } \\
\text { Value (V) }\end{array}$ & Fragments \\
\hline DIOXY & 3.65 & 245.1 & 25 & 6 & $\begin{array}{l}151.0397, \\
121.0293\end{array}$ \\
\hline OXY & 3.83 & 229.1 & 30 & 7 & $\begin{array}{l}105.0341, \\
151.0394\end{array}$ \\
\hline OC & 4.08 & 362.2 & 30 & 1 & $\begin{array}{l}232.0764, \\
250.0872\end{array}$ \\
\hline AVO & 4.26 & 311.2 & 25 & 8 & $\begin{array}{l}135.0443, \\
161.0965\end{array}$ \\
\hline OMC & 4.29 & 291.2 & 15 & 1 & $\begin{array}{l}161.0601, \\
179.0708\end{array}$ \\
\hline $\begin{array}{l}\text { BD-10 } \\
\text { (surrogate) }\end{array}$ & 3.85 & 193.1 & 20 & 8 & $\begin{array}{l}82.0703, \\
110.0650\end{array}$ \\
\hline
\end{tabular}

${ }^{*} \mathrm{CE}$ : Collision Energy 
GC-ECD and GC-MS Analysis. To investigate the formation of volatile halogenated transformation products which are not detected by UHPLC-MS, extracts were also analyzed by GC-ECD (Perkin Elmer Clarus 580 system, Norwalk, CT, USA) and GC (Trace GC Ultra, Thermo Scientific) coupled to a quadrupole ion trap MS fitted with an external ion source (Finnigan Polaris Q). The operating conditions of GC-ECD were as follows:

Target analytes were separated on a capillary column DB5-ms $(30 \mathrm{~m} \times 0.25 \mathrm{~mm} \times 1 \mu \mathrm{m})$. Helium 5.0 was used as a carrier gas at a programmed flow of $1 \mathrm{ml} \mathrm{min}^{-1}$ and nitrogen as make-up gas at a flow of $30 \mathrm{ml} \mathrm{min}^{-1}$. Injection volume was $1 \mu \mathrm{L}$ and injector temperature was $200{ }^{\circ} \mathrm{C}$. Detector temperature was adjusted to $290{ }^{\circ} \mathrm{C}$. The GC oven temperature started at $35^{\circ} \mathrm{C}$, held for $22 \mathrm{~min}$, increased to $145^{\circ} \mathrm{C}$ at $20^{\circ} \mathrm{C} \mathrm{min}^{-1}$ and held for $2 \mathrm{~min}$, then increased to $225^{\circ} \mathrm{C}$ at $20^{\circ} \mathrm{C} \mathrm{min}^{-1}$ and held for $15 \mathrm{~min}$, finally temperature increased to $260{ }^{\circ} \mathrm{C}$ at $10^{\circ} \mathrm{C} \mathrm{min}^{-1}$ and held for $2 \mathrm{~min}$.

The operating conditions for GC-MS were as follows:

The chromatographic separation was accomplished on a TR-5MS capillary column (Thermo Electron, $30 \mathrm{~m} \times 0.25 \mathrm{~mm} \times 0.25 \mu \mathrm{m})$. Samples $(2 \mu \mathrm{L})$ were injected at $280{ }^{\circ} \mathrm{C}$ in splitless mode. Helium was used as a carrier gas at a flow of $1 \mathrm{~mL} \mathrm{~min}^{-1}$. Oven program was adjusted according to U.S.EPA Method 551.1 (1995). Data was recorded in the full scan mode in the mass range $\mathrm{m} / \mathrm{z}$ $50-600$.

\section{RESULTS AND DISCUSSION}

Performance of the Analytical Method for Measuring UV filters in Seawater. An analytical method that allows measuring UV filters in seawater pools at environmental levels was optimized. UV filters detected in samples were identified based on matching the retention times and the relative intensity ratio of transition ions with those of the standard. Quantitation was performed using the ion transition representing the highest abundance. The performance parameters of the analytical method are presented in Table S2.

Table S2. LLE-LC-MSMS method performance characteristics for the analysis of UV filters 


\begin{tabular}{|l|l|l|l|l|l|l|}
\hline Analyte & $\begin{array}{l}\text { Recovery (\%) } \\
(\mathbf{n = 3 )}\end{array}$ & $\begin{array}{l}\text { Precision (\%) } \\
(\text { repeatability) } \\
(\mathbf{n = 3})\end{array}$ & $\begin{array}{l}\text { Linearity } \\
\left(\mathbf{r}^{2}\right)\end{array}$ & $\begin{array}{l}\text { Range } \\
(\mathbf{n g} / \mathbf{L})\end{array}$ & $\begin{array}{l}\text { LOD } \\
(\mathbf{n g} / \mathbf{L})\end{array}$ & $\begin{array}{l}\text { LOQ } \\
(\mathbf{n g} / \mathbf{L})\end{array}$ \\
\hline BP-3 & 93 & 13 & 0.997 & $5-1000$ & 1 & 5 \\
\hline BP-8 & 89 & 16 & 0.992 & $10-1000$ & 8 & 20 \\
\hline Avobenzone & 97 & 8 & 0.998 & $15-1000$ & 5 & 15 \\
\hline OMC & 102 & 11 & 0.998 & $25-1000$ & 5 & 15 \\
\hline OC & 117 & 14 & 0.995 & $20-1000$ & 5 & 15 \\
\hline BP-d10 & 94 & 10 & 0.991 & $10-1000$ & 10 & 30 \\
\hline
\end{tabular}

Method accuracy was validated by calculating the percent recovery using nine determinations over three concentration levels covering the specified range. Recovery ranged between 89 and $117 \%$. Repeatability was evaluated using 9 sample solutions at three different concentration levels (3 replicates per concentration level). Repeatability relative standard deviation (RSD) ranged between 8 and $16 \%$. The range covered 70 to $130 \%$ of the expected test concentrations. Within the studied concentration range, the calibration curves were linear $\left(r^{2}>0.99\right)$. Limits of detection (LOD) were determined as a signal-to-noise ratio 3:1 and ranged between 1 and $10 \mathrm{ng}$ $\mathrm{L}^{-1}$. Limits of quantitation (LOQ) were determined based on a signal-to-noise ratio 10:1. LCMS/MS analysis was demonstrated to be reliable for the identification and quantification of the five studied UV filters in seawater swimming pools.

Occurrence of UV filters in seawater swimming pools. The concentrations of UV filters occurring in the pool water samples collected consecutively at $1-\mathrm{h}$ intervals starting from the pool filling and opening in the morning, were measured by analyzing samples using the validated method based on LLE extraction and further UHPLC-ESI-MS/MS separation and detection. The physicochemical parameters, free and combined chlorine, and bromide content of water in the pools are summarized in Table S3.

Table S3. Physicochemical parameters, bromide concentration, free and combined chlorine

\begin{tabular}{|c|c|c|c|c|c|c|}
\hline Pool & $\begin{array}{l}\text { Temperature } \\
\left({ }^{\circ} \mathrm{C}\right)\end{array}$ & $\mathrm{pH}$ & $\begin{array}{l}{[\mathrm{Br}-]} \\
\left(\mathrm{mg} \mathrm{L}^{-1}\right)\end{array}$ & $\begin{array}{l}\text { Conductivity } \\
\left(\mathrm{mS} \mathrm{cm}^{-1}\right)\end{array}$ & $\begin{array}{l}\text { Free } \\
\text { Chlorine } \\
\left(\mathrm{mg} \mathrm{L}^{-1}\right)\end{array}$ & $\begin{array}{l}\text { Combined } \\
\text { chlorine (mg } \\
\left.\mathbf{L}^{-1}\right)\end{array}$ \\
\hline Adults' Pool & 26.8 & 8.08 & 73.2 & 56.2 & 1.7 & 0.6 \\
\hline $\begin{array}{l}\text { Children's } \\
\text { Pool }\end{array}$ & 29.6 & 8.04 & 68.1 & 55.7 & 3.1 & 1.8 \\
\hline
\end{tabular}


Since the pools were filled with seawater, $\mathrm{pH}$ was slightly basic (8.08 and 8.04 in the adults' and children's pools, respectively) and bromide contents were relatively high $\left(73.2 \mathrm{mg} \mathrm{L}^{-1}\right.$ and 68.1 $\mathrm{mg} \mathrm{L}^{-1}$ in adults' and children's pool, respectively). Free chlorine residual was $1.7 \mathrm{mg} \mathrm{L}^{-1}$ in the adults' pool and $3.1 \mathrm{mg} \mathrm{L}^{-1}$ in the children's pool. These concentrations are higher than the maximal free chlorine residual recommended by French swimming pool guidelines (between 0.4 and $\left.1.4 \mathrm{mg} \mathrm{L}^{-1}\right){ }^{45}$ Figure 1 shows the evolution of the concentration of UV filters detected in the adults' and children's pools as a function of time.

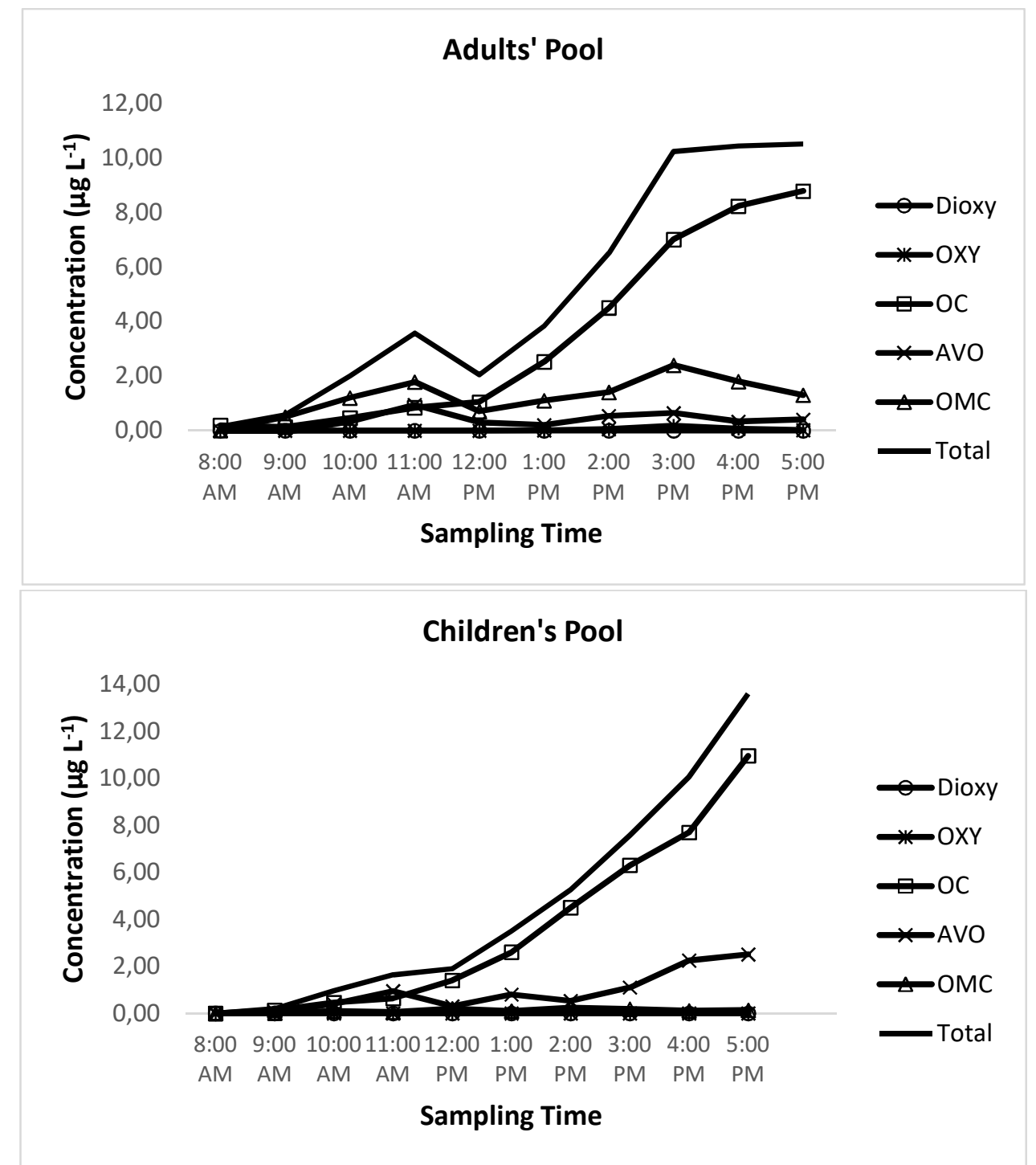

Figure 1: Variation of concentrations of UV filters detected in adults' (upper figure) and children's (lower figure) swimming pools as a function of pool opening hours throughout the sampling day. 
All the analyzed UV filters except DIOXY were detected in the pools. OXY was detected at relatively low concentrations with maximal concentration reaching $180 \mathrm{ng} \mathrm{L}^{-1}$ in the adult's pool. In the literature, the reported concentrations of OXY in swimming pools varied considerably between one study and another with concentrations ranging from the $n g \mathrm{~L}^{-1}$ to the $\mu \mathrm{g} \mathrm{L}^{-1}{ }^{5,7}$ In the present study, OC was the most abundant UV filter with concentrations reaching $8.77 \mu \mathrm{g} \mathrm{L}^{-1}$ and $10.96 \mu \mathrm{g} \mathrm{L}^{-1}$ in the adults' and children's pool, respectively. In both pools, OC showed an accumulating concentration trend, while the other detected UV filters OXY, AVO and OMC witnessed fluctuations in their concentrations. In the adults' pool, OMC represented the second most abundantly occurring UV filter with maximal concentration reaching $2.39 \mu \mathrm{g} \mathrm{L}^{-1}$, while in the children's pool AVO represented the second most abundantly occurring UV filter with a maximal concentration reaching $2.51 \mu \mathrm{g} \mathrm{L}^{-1}$. This partition could be caused by differences in formulations between sunscreens intended to be applied by adults than those intended to be applied by children. Overall, the concentration of UV filters detected in the children's pool (13.60 $\left.\mu \mathrm{g} \mathrm{L}^{-1}\right)$ was slightly higher than that detected in the adults' pool $\left(10.49 \mu \mathrm{g} \mathrm{L}^{-1}\right)$. These findings are in agreement with findings about the occurrence of UV filters in swimming pools in Germany. ${ }^{10}$ In this latter study, authors detected OC as the most abundant UV filter in the studied pool with higher concentrations of UV filters detected in babies' pool in comparison to swimmers' pool. Since sunscreens usually contain combinations of multiple UV filters, the discrepancy in variation in the concentrations of the different UV filters in pools could be partially caused by different stability/reactivity characteristics of the UV filters in the presence of oxidants. $^{3}$ In German swimming pools, where pool disinfection guidelines recommend maintaining free residual chlorine level between 0.3 and $0.6 \mathrm{mg} \mathrm{L}^{-1}$, relatively high concentrations of UV filters reaching $40 \mu \mathrm{g} \mathrm{L}{ }^{-1}$ were reported in pools. ${ }^{10}$ In other countries where higher levels of residual chlorine are recommended, lower concentrations of UV filters reaching the $n g \mathrm{~L}^{-1}$ range were reported. ${ }^{3}$

\section{Chlorination reactions of $\mathrm{UV}$ filters in reconstituted seawater}

Reactivity of the UV filters. The reactivity of the five UV filters in the presence of excess chlorine in seawater at the ratios molar 1:10, 1:25, and 1:100 (UV filter:chlorine) was investigated. The reactive UV filters OXY, DIOXY, AVO and OMC were unstable when chlorine was added in excess at ratios 1:10, 1:25, and 1:100 (Figure 2). 
R 1:10

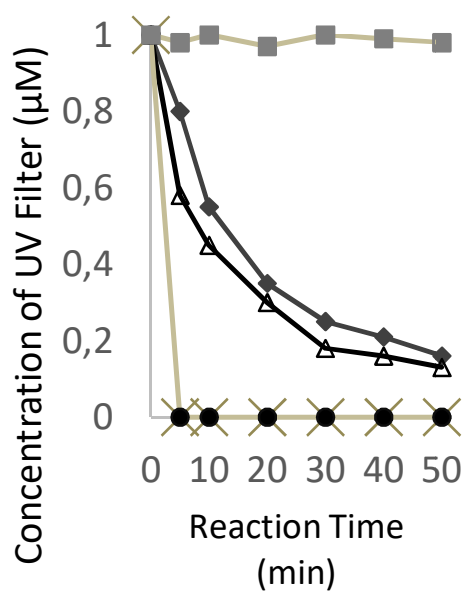

R 1:25

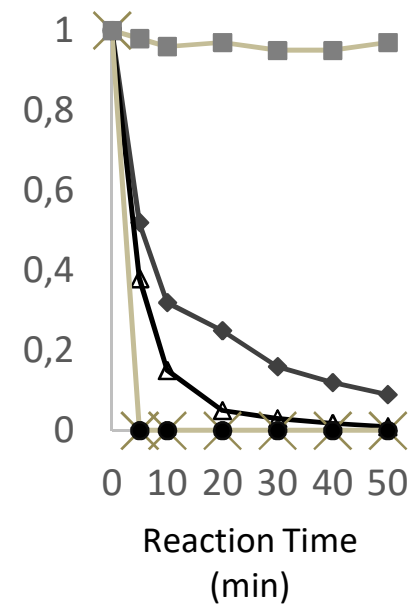

R 1:100

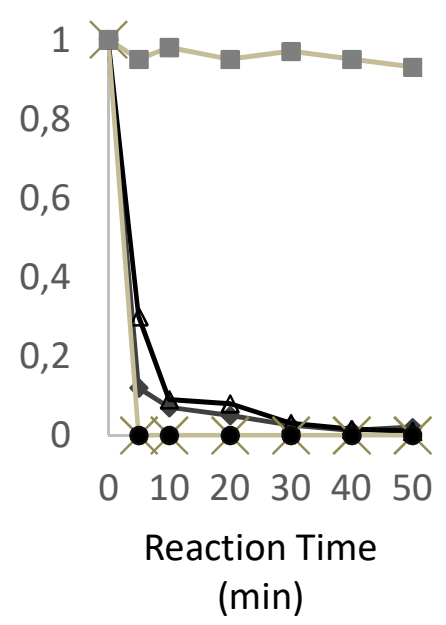

Figure 2: Disappearance of UV filters in seawater after the addition of chlorine in excess at three different ratios (UV filter:Chlorine 1:10, 1:25, and 1:100)

On the contrary, the concentration of OC remained constant even when 1000-fold excess of chlorine was added. This difference in reactivity towards halogenating/oxidizing agents is related to structural differences between the UV filters. While all of the four reactive UV filters have electron-donating groups in their molecular structures making them susceptible to being attacked by electrophilic species, OC has a cyano group (strongly electron-withdrawing) and an ester group (moderately withdrawing) making the molecule less susceptible to electrophilic attacks. This stability of OC can be advantageous from the point of view that the UV filter is still intact performing its functions in screening UV radiation. Among the reactive UV filters, the benzophenone UV filters DIOXY and OXY were degraded very rapidly followed by the slower reacting UV filters AVO and OMC, respectively (Figure 2). Chlorination experiments carried out under solar irradiation resulted in roughly similar kinetics of disappearance of reactive UV filters as when no solar irradiation was applied (Figure S1). 
OMC

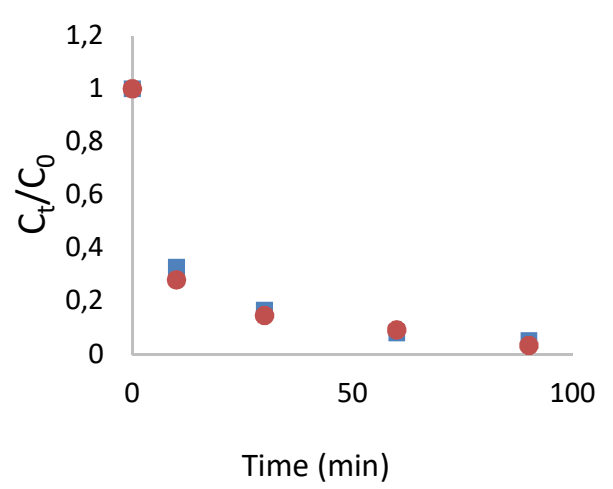

OC

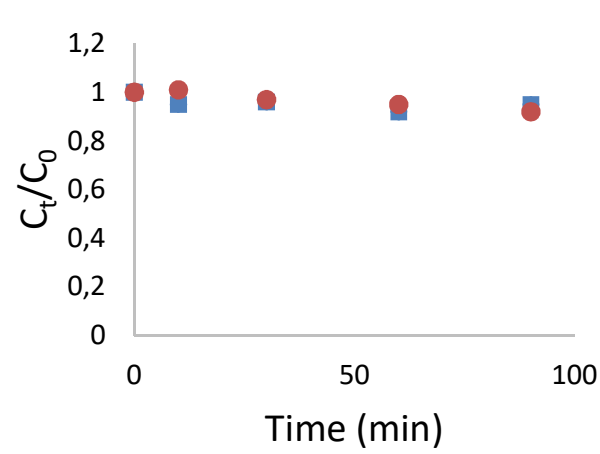

AVO

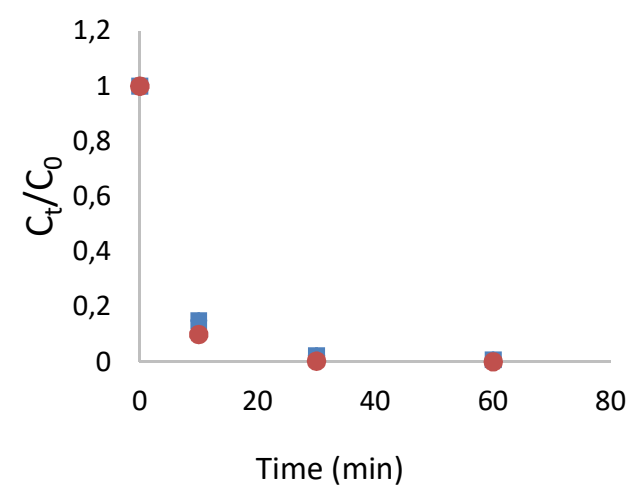

OXY and DIOXY

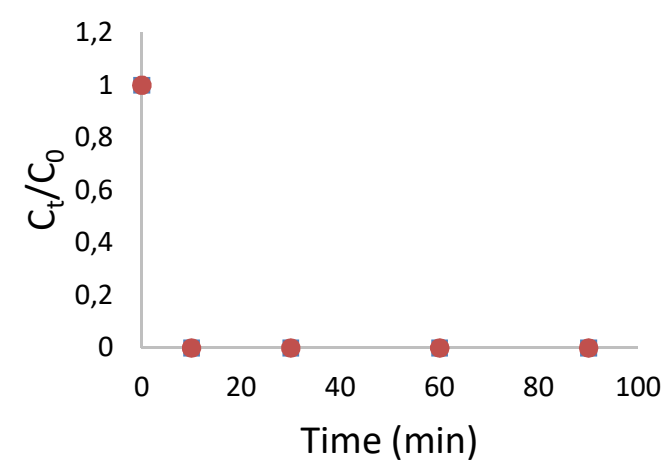

Figure S1. Disappearance of UV filters in chlorination reactions with solar irradiation (red points) and without solar irradiation (blue points). Chlorination reactions were conducted according to the protocol described in the manuscript at a ratio of UV filter:chlorine concentration of 1:25.

OC was stable even when solar irradiation was applied during chlorination reactions. Although these findings suggest that bromination is the main process leading to the disappearance of reactive UV filters in chlorinated seawater pools, a slow photolability cannot be excluded based on this finding.

Formation of brominated byproducts from the reactive UV filters. The chlorination of UV filters DIOXY, AVO and OMC in seawater generated brominated transformation products. No chlorinated transformation products were detected. The detection of brominated species only can be explained by the formation of bromine upon the addition of chlorine to seawater. In seawater, chlorine rapidly reacts with bromide to produce bromine which is a faster oxidant. ${ }^{27}$ The reaction takes places as follows: ${ }^{27}$ 


$$
\begin{array}{ll}
\mathrm{HOCl}+\mathrm{Br}^{-} \rightarrow \mathrm{HOBr}+\mathrm{Cl}^{-} & k_{1}=(1.55-6.84) \cdot 10^{3} \mathrm{M}^{-1} \mathrm{~s}^{-1}(1) \\
\mathrm{ClO}^{-}+\mathrm{Br}^{-} \rightarrow \mathrm{BrO}^{-}+\mathrm{Cl}^{-} & k_{2}=9.10^{-4} \mathrm{M}^{-1} \mathrm{~s}^{-1}(2)
\end{array}
$$

This reaction is in agreement with the nucleophilic character of the reacting species since bromide ions are more nucleophilic than chloride ions. Bromine reactions are often several orders of magnitude faster than those of chlorine. ${ }^{35}$ Bromine species that could contribute to bromination reactions of organic compounds include $\mathrm{HOBr}$ and $\mathrm{OBr}^{-}$which represent the most abundant species. ${ }^{27}$ Other species like $\mathrm{Br}_{2}, \mathrm{Br}_{2} \mathrm{O}, \mathrm{BrOCl}$, and $\mathrm{BrCl}$ which are more reactive than $\mathrm{HOBr}$ and $\mathrm{OBr}^{-}$have been also shown to contribute to the bromination of some organic compounds. ${ }^{46}$ Table 2 shows the equilibrium concentrations of bromine species when seawater ( $67 \mathrm{mg} \mathrm{L}^{-1}$ of bromide, $\mathrm{pH} 8.05$ ) is chlorinated with $2 \mathrm{mg} \mathrm{L}^{-1}$ active chlorine, as calculated using PHREEQC ${ }^{27}$.

Table 2. Molar concentrations of bromine species at equilibrium in seawater containing $67 \mathrm{mg} \mathrm{L}^{-1}$ bromide and $20 \mathrm{~g} \mathrm{~L}^{-1}$ chloride at $\mathrm{pH} 8.05$ when chlorinated with $2 \mathrm{mg} \mathrm{L}^{-1}\left(=2.82 \times 10^{-5} \mathrm{M}\right)$ active chlorine. Calculations were performed using PHREEQC based on equilibrium constants described by Heeb et $a l^{27}$

\begin{tabular}{ll}
\hline Bromine Species & Concentration (M) \\
\hline $\mathrm{HOBr}$ & $3.85 \times 10^{-5}$ \\
$\mathrm{OBr}$ & $1.67 \times 10^{-5}$ \\
$\mathrm{Br}_{2}$ & $2.73 \times 10^{-8}$ \\
$\mathrm{Br}_{2} \mathrm{Cl}$ & $1.83 \times 10^{-8}$ \\
$\mathrm{Br}_{2} \mathrm{O}$ & $1.08 \times 10^{-8}$ \\
$\mathrm{BrCl}^{-8}$ & $7.61 \times 10^{-10}$ \\
$\mathrm{Br}_{3}^{-}$ & $3.29 \times 10^{-10}$ \\
$\mathrm{BrCl}_{2}^{-}$ & $2.55 \times 10^{-10}$ \\
$\mathrm{BrOCl}^{-10}$ & $2.44 \times 10^{-12}$ \\
\hline
\end{tabular}

In these conditions, the concentration of $\mathrm{HOBr}$ is about 3 orders of magnitude higher than $\mathrm{Br}_{2}$ and $\mathrm{Br}_{2} \mathrm{O}, 5$ orders of magnitude higher than $\mathrm{BrCl}$ and $\mathrm{Br}_{3}{ }_{3}$, and 7 orders of magnitude higher than BrOCl (Table 2). Although these latter bromine species are less abundant compared to $\mathrm{HOBr}$, their contribution to bromination reactions have been shown to become significant under certain conditions. ${ }^{46}$ The importance of these species as brominating agents tends to increase when organic substrates are less nucleophilic and thus less reactive towards $\mathrm{HOBr}$ and $\mathrm{OBr}^{-}{ }^{46,47}$ Considering the observed reactivity of the UV filters investigated in the present study (Figure 2), it can be postulated that the reactivity of the fast reacting OXY and DIOXY is less likely to involve species other than the abundant $\mathrm{HOBr}$ and $\mathrm{OBr}^{-}$. However, with the slower reacting AVO and OMC, which are far less nucleophilic than the benzophenone-type UV filters OXY and 
DIOXY, the contribution of species other than $\mathrm{HOBr}$ and $\mathrm{OBr}^{-}$to bromination reactions could be plausible.

DIOXY undergoes a series of aromatic electrophilic substitutions leading to the formation of mono-, di-, tri- and tetra- brominated DIOXY. Tribrominated oxidized DIOXY originates from tribrominated DIOXY undergoing Baeyer-Villiger oxidation. This oxidation converts the ketone group to an ester group. Baeyer-Villiger oxidation has been described in the chlorination transformation pathways of other benzophenone-derivative UV filters including $\mathrm{OXY}^{48}$ and sulisobenzone (BP-4). ${ }^{49,50}$ Further bromination of the tribrominated oxidized DIOXY would lead to the formation of tetra brominated oxidized DIOXY (unstable intermediate). The cleavage of the latter leads to the formation of 2,4,6-tribromo-3-methoxyphenol (TBMP) and 2,4dibromosalicylic acid which were both detected as stable transformation products. The identification of TBMP was performed by matching the retention times and mass spectra of the detected product with a pure standard. The structural identification of the second moiety of DIOXY as dibromosalicylic acid was confirmed by matching the mass spectra and retention time with the bromination product of salicylic acid. Due to the ortho- and para-directing effects of hydroxyl group, and the meta-directing effect of the carboxyl group, 2,4-dibromosalicylic acid is likely to be formed. ${ }^{51}$ The transformation pathway of OXY in chlorinated seawater was described elsewhere. ${ }^{48}$ Similar to DIOXY, OXY undergoes a sequence of aromatic electrophilic substitution reactions on the phenolic ring before the separation of the two aromatic rings and the formation of TBMP. However, no tetra-brominated transformation product was detected among the transformation products of OXY. In contrast, DIOXY possesses two phenolic rings that undergo a sequence of bromine substitution reactions leading to the formation of a tetrabrominated transformation product. Two brominated DBPs namely bromoform and bromal hydrate were formed from DIOXY. Bromoform and bromal hydrate were detected by GC-ECD analysis and their identification was confirmed by GC-MS analysis and by matching their retention time with pure standards. The formation of these two aliphatic brominated compounds result from the cleavage of the phenolic rings. ${ }^{52}$ Based on the identified byproducts, the transformation pathway of DIOXY was proposed (Scheme 1). The tentative structural assignments are presented along with the formula of the molecular ion detected, the measured accurate mass and the monoisotopic calculated exact mass. Four positional isomers 
(regioisomers) were detected for the monobrominated DIOXY. These isomers had the same exact mass and exhibited the same mass spectra but appeared at slightly different retention times.

\section{Scheme 1. Reaction pathway of DIOXY in chlorinated seawater, based on identified} byproducts by UPLC-ESI-MS and GC-MS

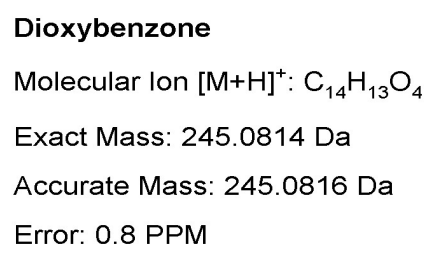<smiles>COc1c(Br)cc(C(=O)c2cc(Br)cc(Br)c2O)c(O)c1Br</smiles>

Baeyer-Villiger Oxidation Tribrominated Oxidized Dioxybenzone Molecular Ion [M-H]': $\mathrm{C}_{14} \mathrm{H}_{8} \mathrm{O}_{5} 79 \mathrm{Br}_{3}$ Exact Mass: $492.7927 \mathrm{Da}$ Accurate Mass: $492.7909 \mathrm{Da}$ Error: 3.6 PPM<smiles>COc1c(Br)cc(OC(=O)c2ccccc2O)c(O)c1Br</smiles> 


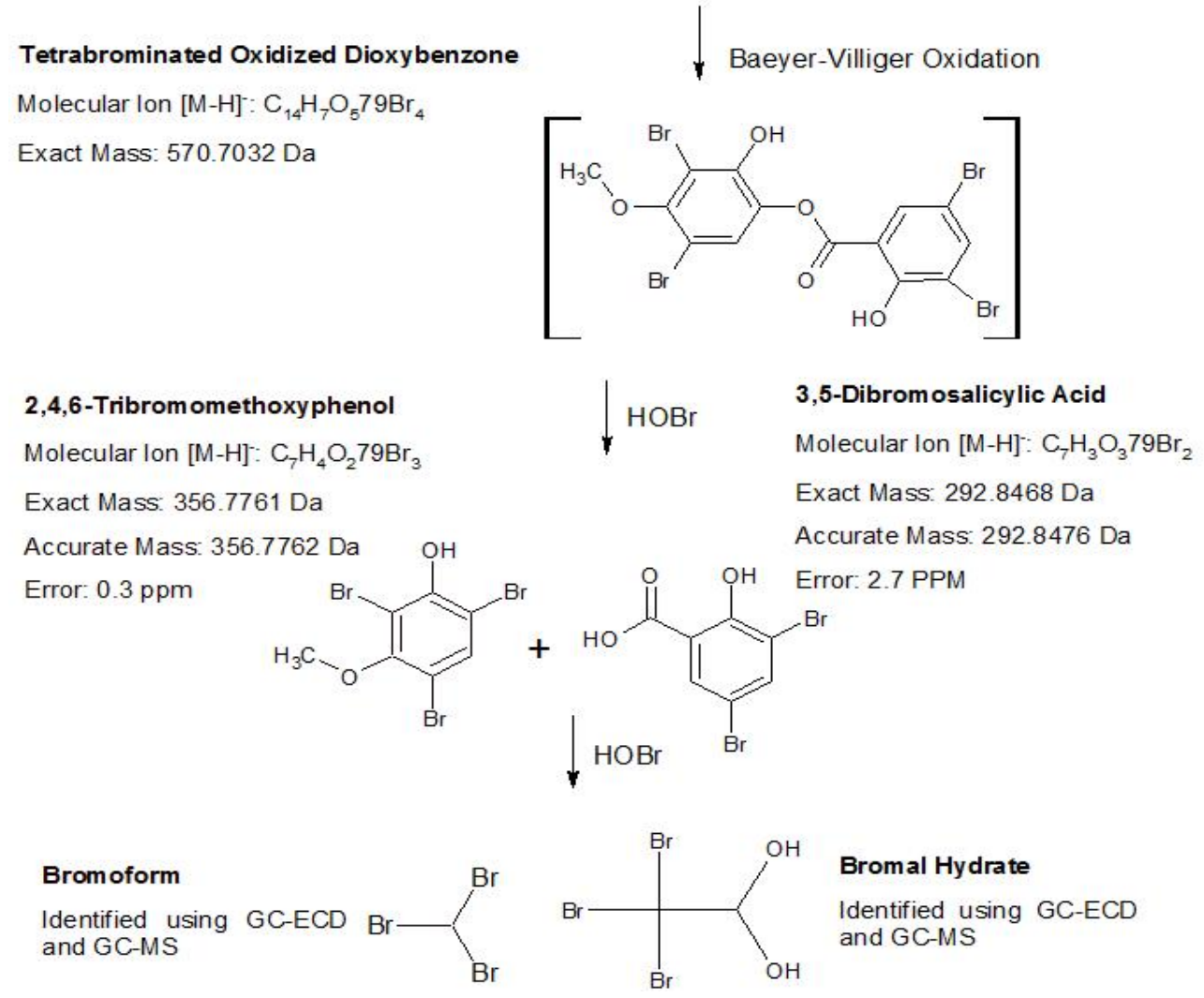

The formation of four isomers is the result of electrophilic substitution taking place on the orthoand para-positions of each of the two phenolic moieties present in DIOXY (Spectra presented in SI-4).

The isomers in which bromine substitution occurred at the level of the phenolic ring holding the methoxy group had superior peaks than isomers in which substitution occurred on the phenolic moiety devoid of additional electron-donating groups. The presence of methoxy group activates the phenolic ring and enhances electrophilic substitution reactions. Two isomers are generated when substitution occurs at any of the phenolic rings due to the ortho- and para-directing effect of hydroxyl group. ${ }^{51}$

The reactions of OMC in chlorinated seawater generated monobrominated and dibrominated substitution products (Scheme 2). Four isomers were detected corresponding to monobrominated OMC. The four isomers are believed to originate from $\mathrm{OMC}(\mathrm{Z})$ and $(\mathrm{E})$ each undergoing bromination at two different sites. Two isomers of dibrominated OMC were detected (SI-5). 
SI-4. Mass Spectra of DIOXY Transformation Products

\section{MSMS Spectrum of Monobrominated DIOXY (2 major isomers)}

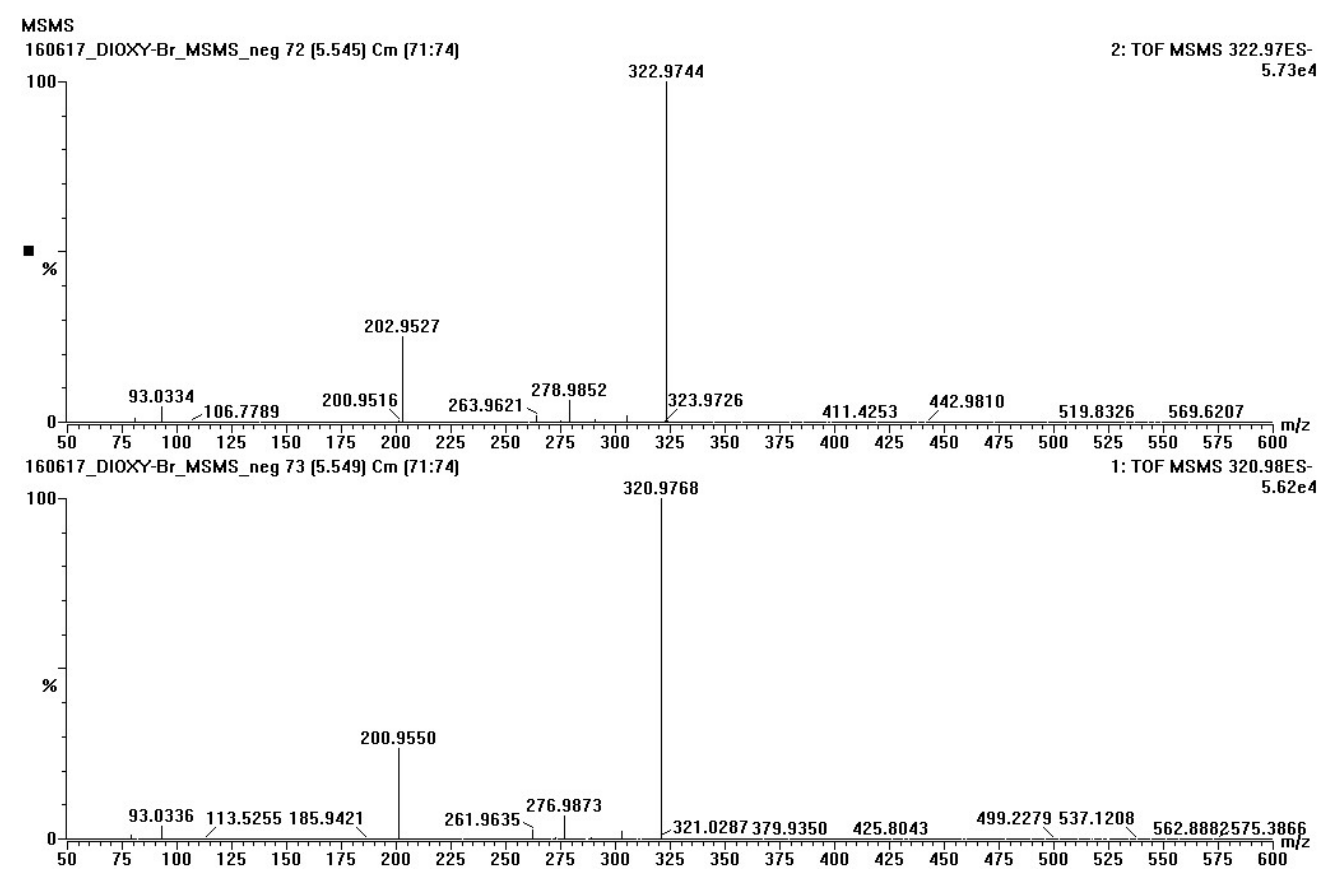

\section{MSMS Spectrum of Monobrominated DIOXY ( 2 minor isomer)}

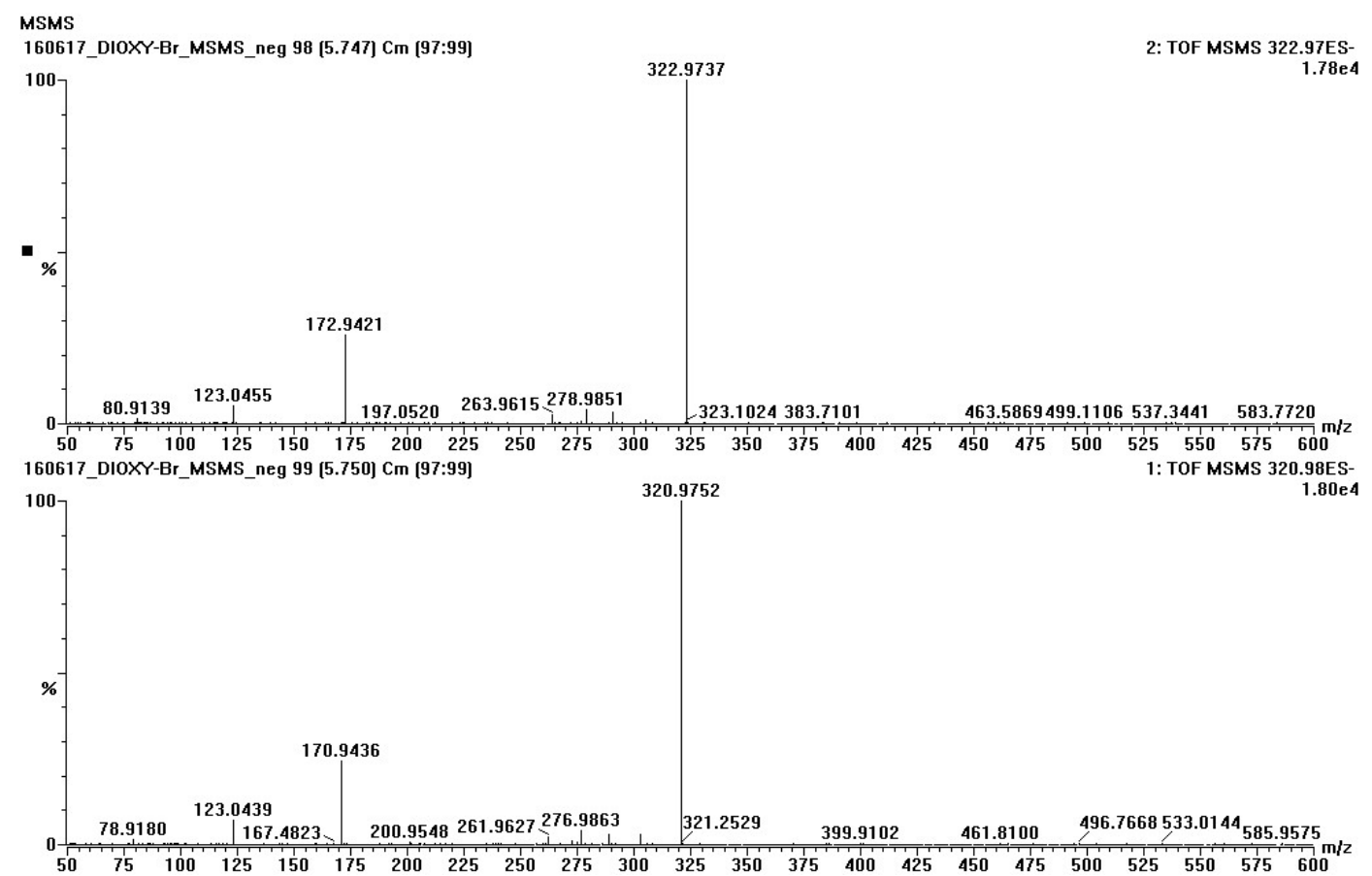


MSMS

160617_DIOXY-Br2_MSMS_neg 72 [5.821] Cm [72:75]

1

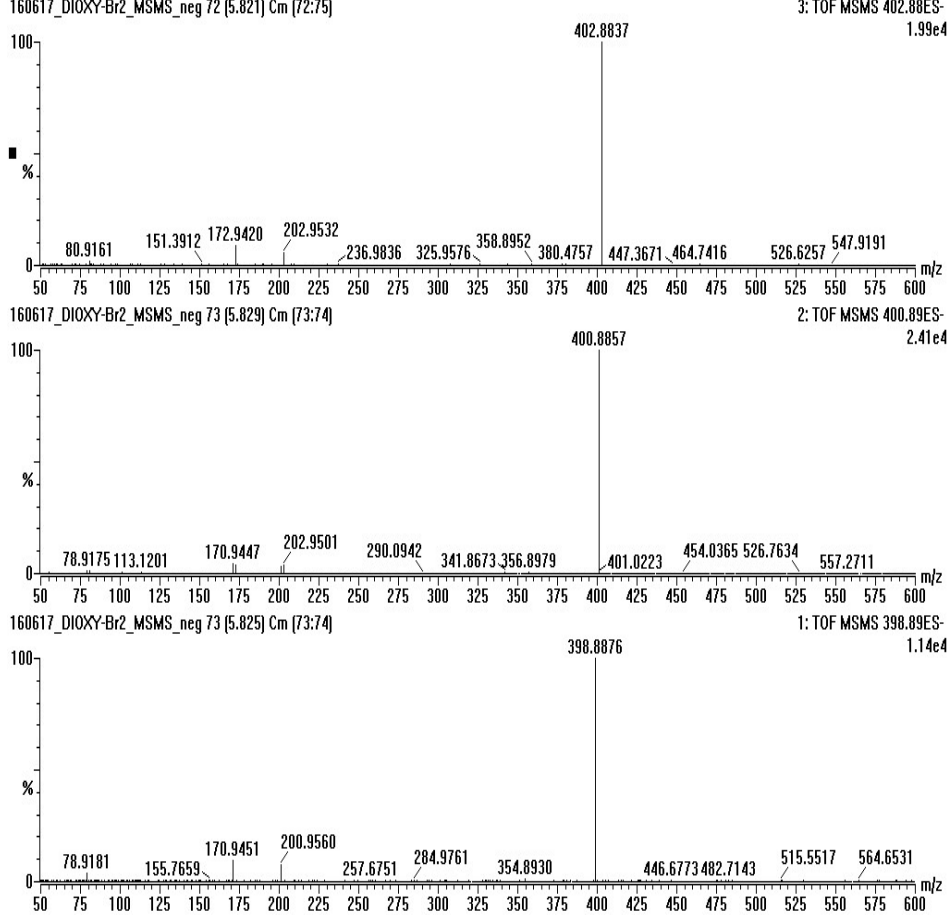

\section{MSMS Spectrum of tribrominated DIOXY}

MSMS

160617 _Ll0XY_Br3_MSMS_neg 24 [6.366] Cm [24:26]

11

$\%$

282.8633

282.8630

(10) 160617_DIOXYYBr3_MSMS__neg 24|6.362] Cm [24:25]

3: TOF MSMS 480.79ES-

100

$\%$

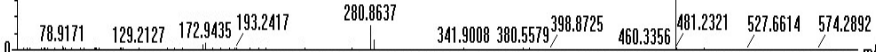

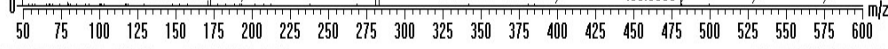
160617 _Dl0XY-Br3_MSMS__eg 25 [6.373] Cm [25]

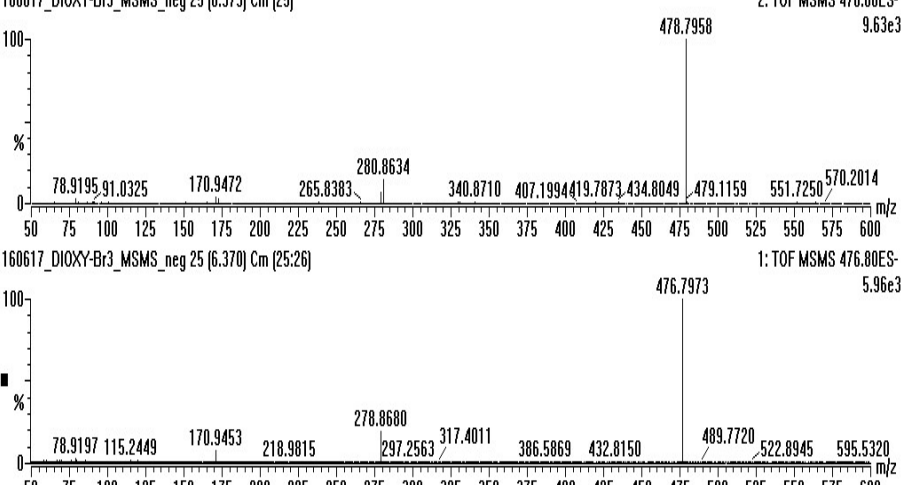

963

$\begin{array}{lllllllllllllllllllllll}50 & 75 & 100 & 125 & 150 & 175 & 200 & 225 & 250 & 275 & 300 & 325 & 350 & 375 & 400 & 425 & 450 & 475 & 500 & 525 & 550 & 575 & 600\end{array}$ 


\section{MS Spectrum of tribrominated oxidized DIOXY}

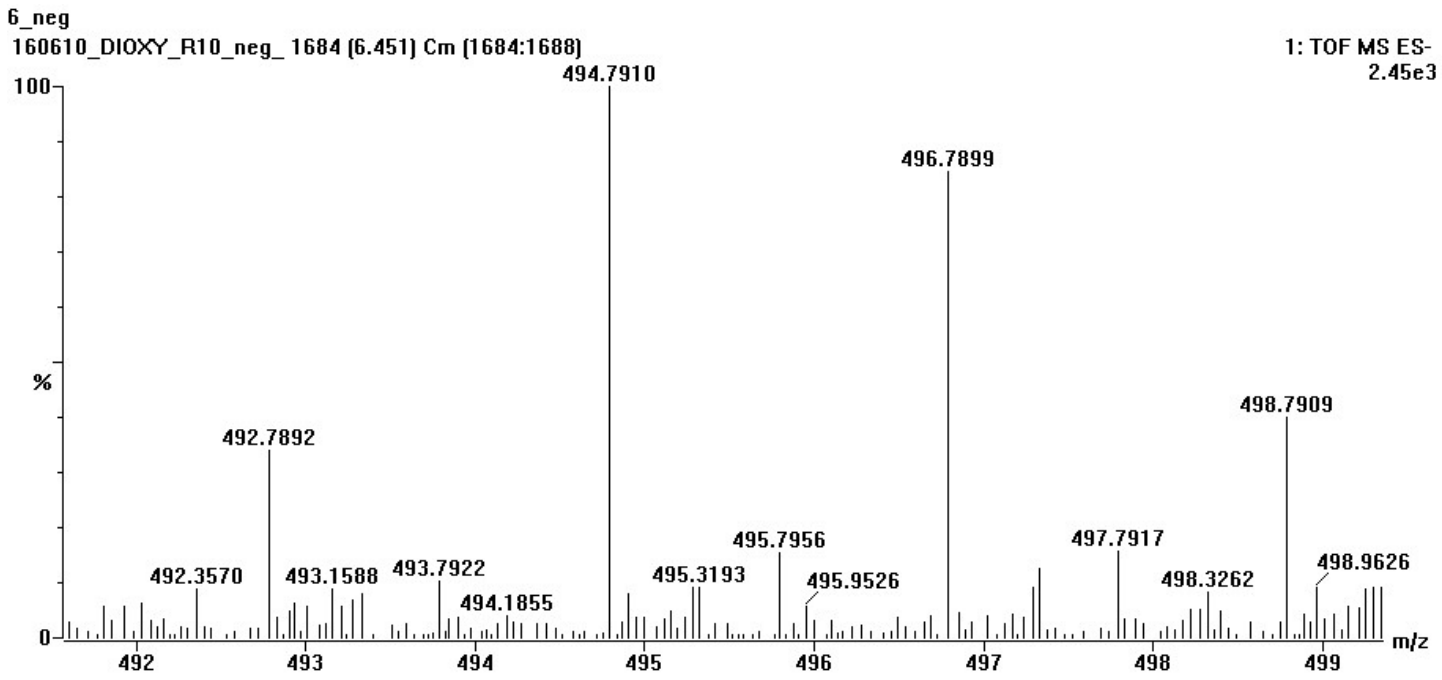

\section{MSMS Spectrum of tetrabrominated DIOXY}

\section{MSMS}

160617_DIOXY-Br4_MSMS_neg 52 [6.486] Cm [52] 100

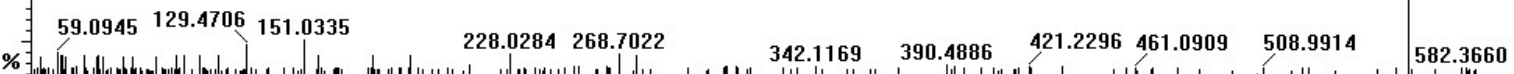

\%

5. TOF MSMS 562.70ES 562.695 \% 0 = 160617_DIOXY-Br4_MSMS_neg 52 [6.482] Cm [52:53]

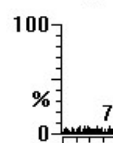

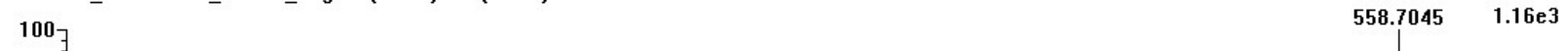
ם

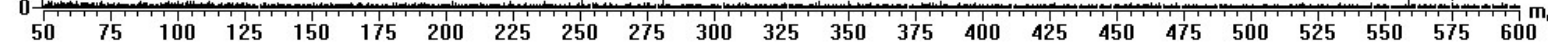
160617_DIOXY-Br4_MSMS_neg 52 [6.475] Cm [52:54] 2: TOF MSMS 556.71ES-

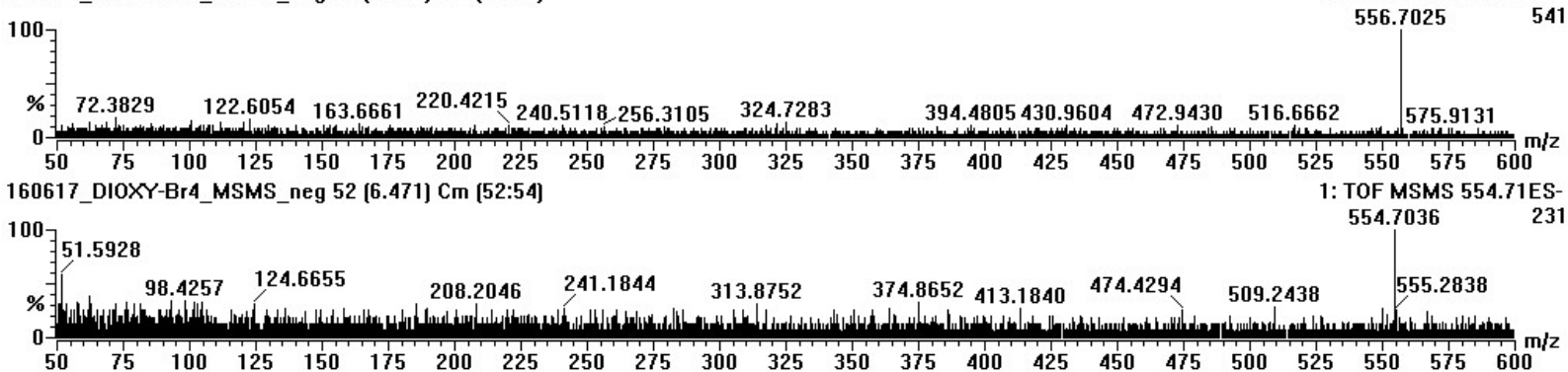




\section{MS Spectrum of dibrominated salicylic acid}

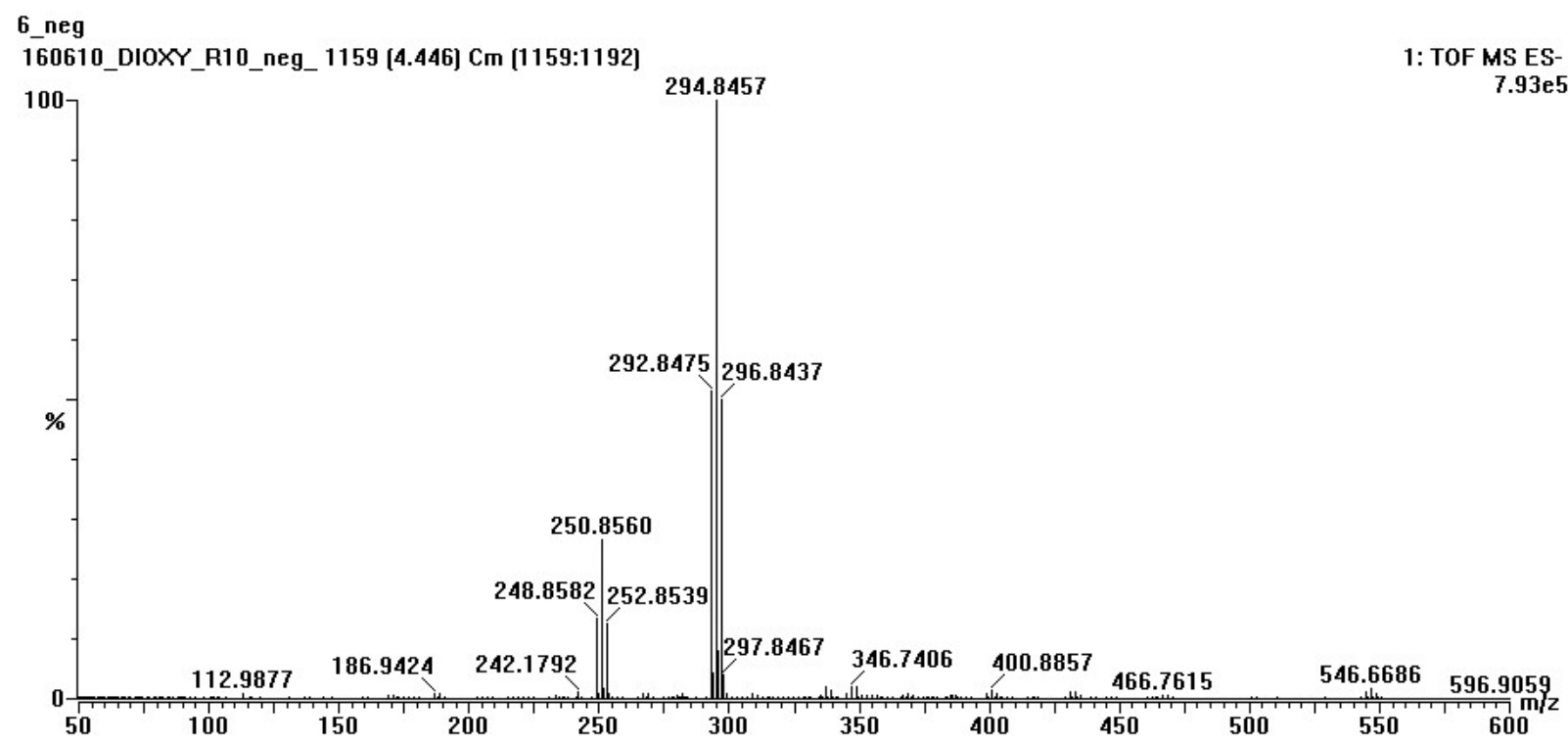

\section{MS Spectrum of 2,4,6-Tribromo-3-methoxyphenol (TBMP)}

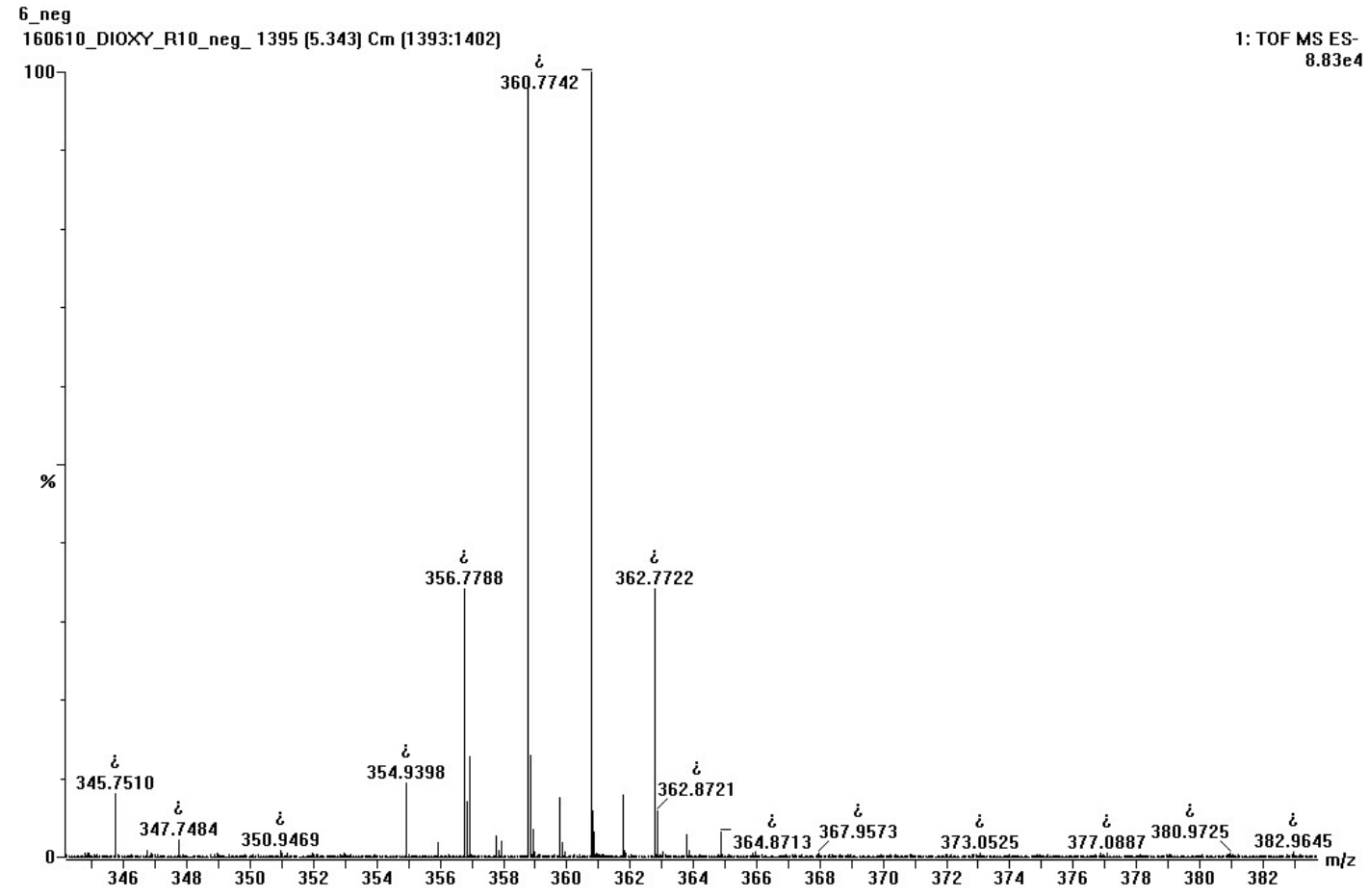

Two isomers of dibrominated OMC were detected. These findings are in agreement with the study of Nakajima et al. which detected four monochlorinated OMC isomers and two 
dichlorinated OMC isomers upon chlorination of OMC in freshwater. ${ }^{21}$ Monobrominated and dibrominated substitution products of AVO were detected (Scheme 3).

\section{SI-5. Mass Spectra of OMC Transformation Products}

\section{MSMS Spectrum of Monobrominated OMC}

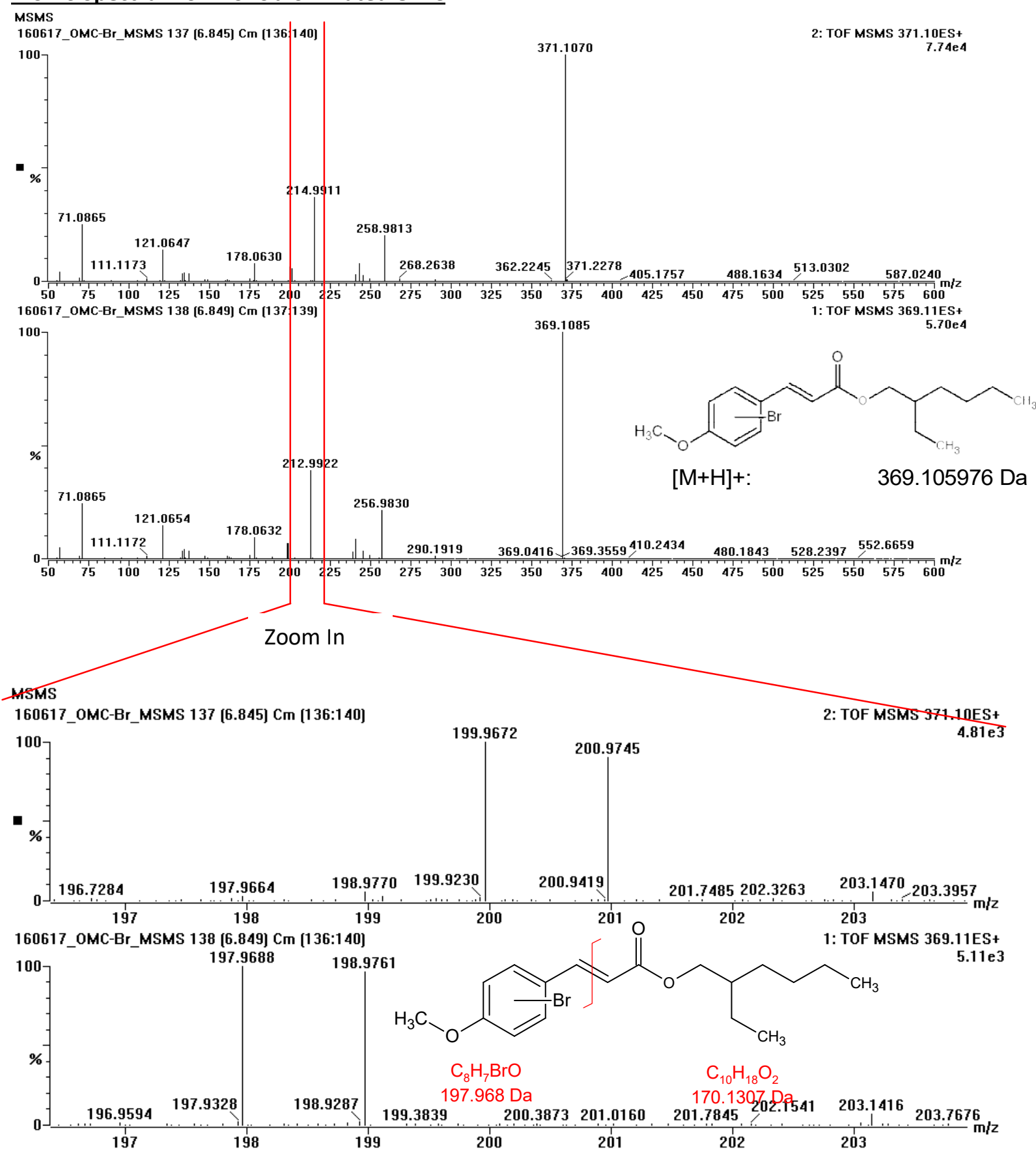




\section{MS Spectrum of Dibrominated OMC}

\section{8_pos}

160610_OMC_R10_pos 1703 [6.522] Cm [1699:1708]

$-$

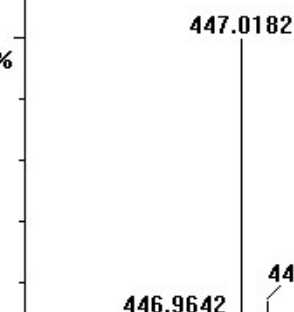

447.0182

447.1190

447

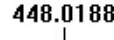

$48.1022 \quad 448.5828$

449.0141

1: TOF MS ES+

$2.27 \mathrm{e} 4$<smiles>CCCCC(CC)COC(=O)/C=C/c1ccc(Br)cc1Br</smiles>

$[\mathrm{M}+\mathrm{H}]+$ :

447.016481 Da

451.0122

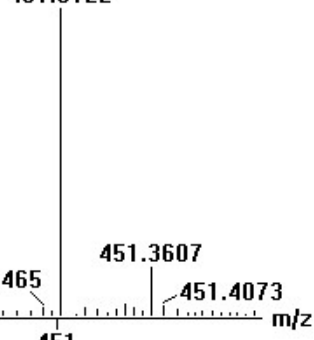

Scheme 2. Reaction pathway of OMC in chlorinated seawater, based on identified byproducts by UPLC-ESI-MS and GC-MS

MSMS Spectrum of Dibrominated OMC

MSMS

160617_OMC-Br2_MSMS_2 134 [6.531] Cm [134] 3: TOF MSMS 451.01ES+
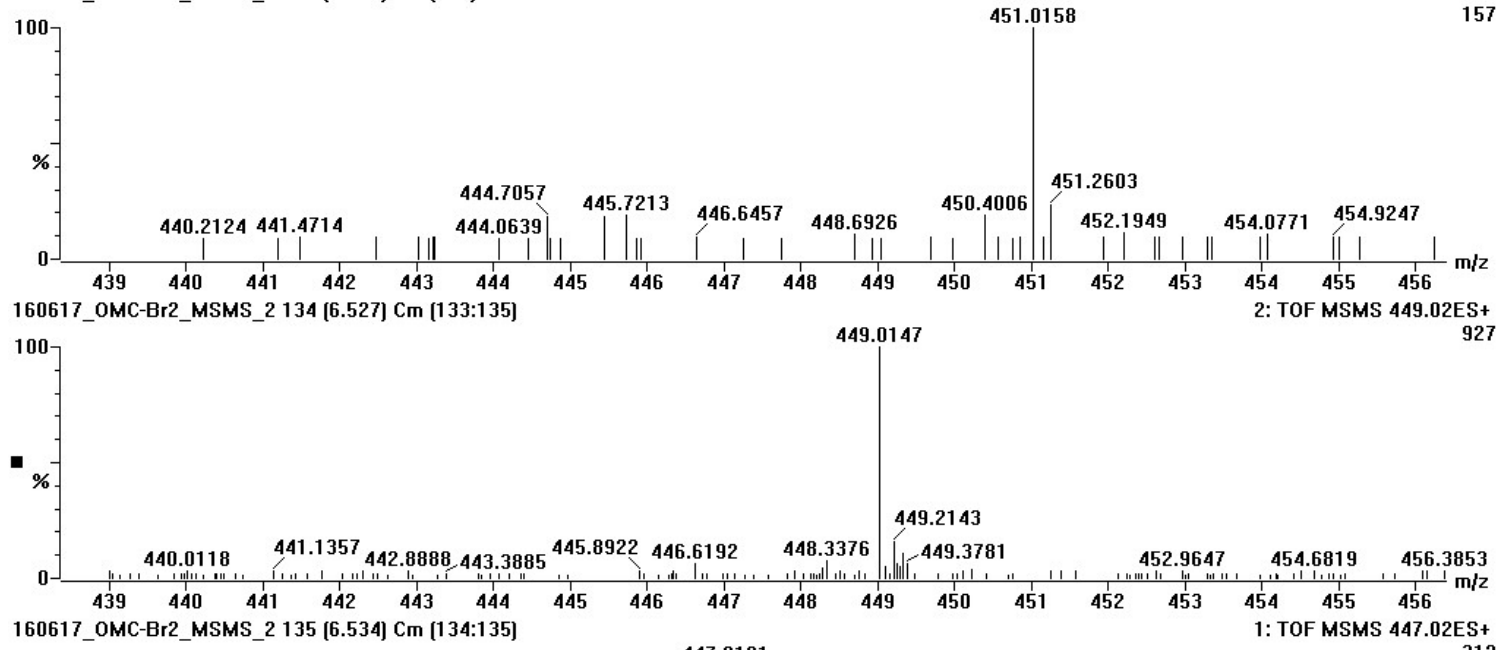
160617 OMC-Br2 MSMS $2135[6.534] \mathrm{Cm}[134: 135]$

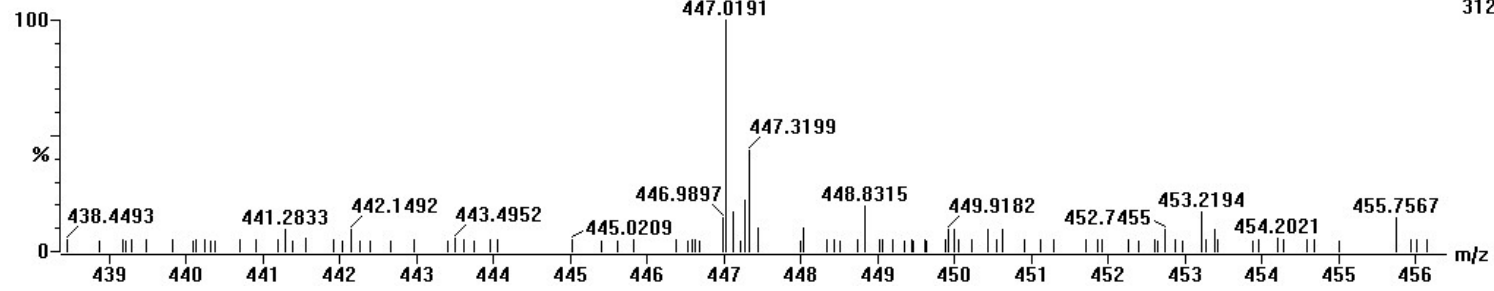


Scheme 2. Reaction pathway of OMC in chlorinated seawater, based on identified byproducts by UPLC-ESI-MS and GC-MS

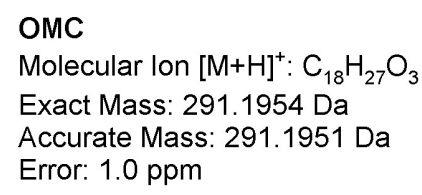

(E) and (Z) isomers<smiles>CCCCC(CC)COC(=O)/C=C/c1ccc(OC)cc1</smiles>

Monobrominated OMC

Molecular lon $[\mathrm{M}+\mathrm{H}]^{+}: \mathrm{C}_{18} \mathrm{H}_{25} \mathrm{O}_{3} 79 \mathrm{Br}$

Exact Mass: $369.1059 \mathrm{Da}$

Accurate Mass: $369.1055 \mathrm{Da}$

Error: $1.0 \mathrm{ppm}$
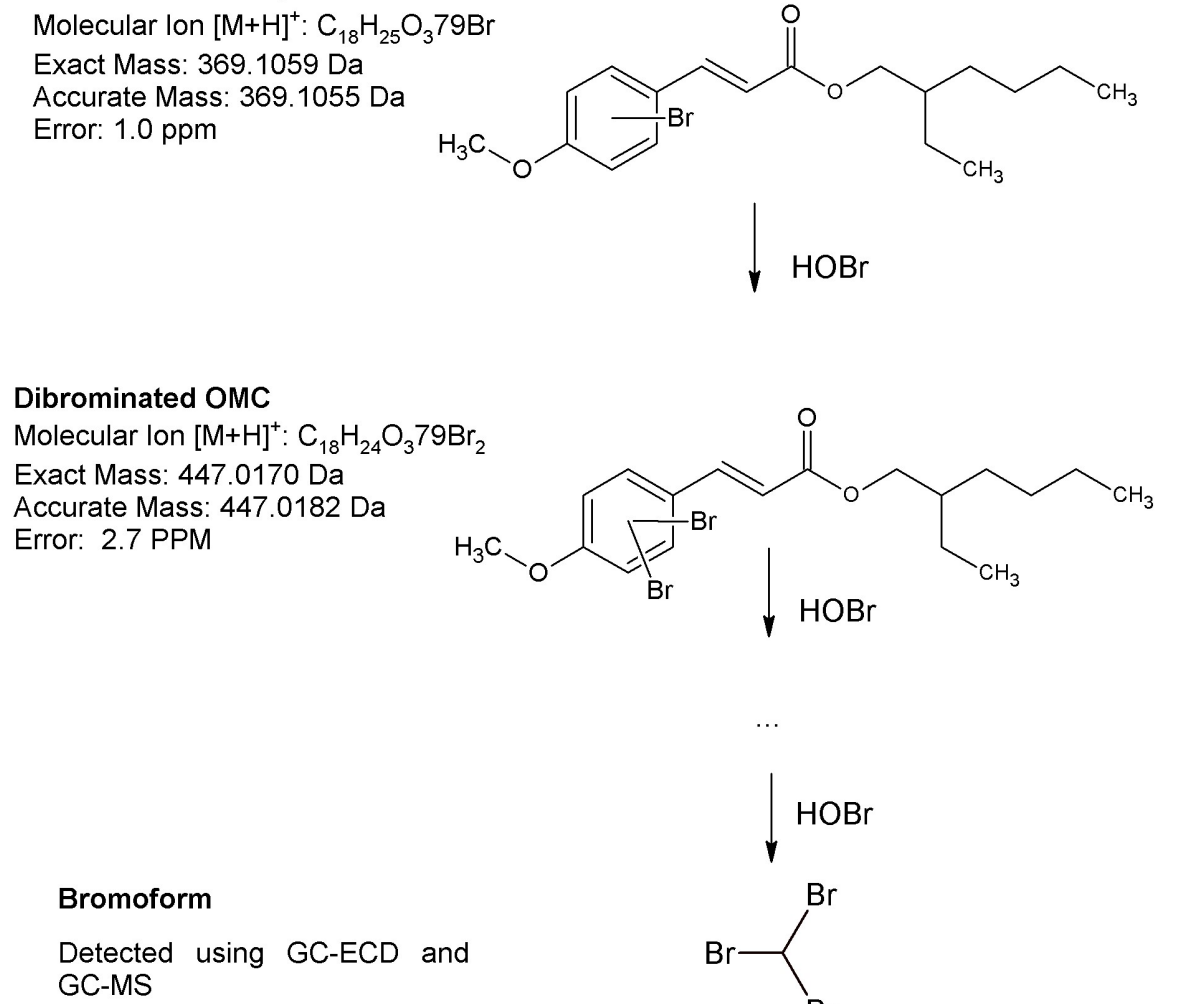

Detected using GC-ECD and GC-MS

\section{Bromoform}

The analysis of the MS/MS spectra of these transformation products of AVO showed that the electrophilic substitution takes place on carbon alpha to the carbonyl carbon rather than the aromatic ring (mass spectra presented in SI-6). The presence of keto-enol tautomerism in AVO makes it highly reactive towards electrophilic species since the $\mathrm{C}=\mathrm{C}$ of an enol is very electron rich (hydroxyl substituent) making it strongly nucleophilic. Chlorination reactions of OXY, DIOXY, OMC, and OC in seawater resulted in the formation of bromoform. Bromal hydrate was also detected at relatively low concentrations in seawater chlorination reactions of OXY and DIOXY. 
Scheme 3. Reaction pathway of AVO in chlorinated seawater, based on identified byproducts by UPLC-ESI-MS and GC-MS

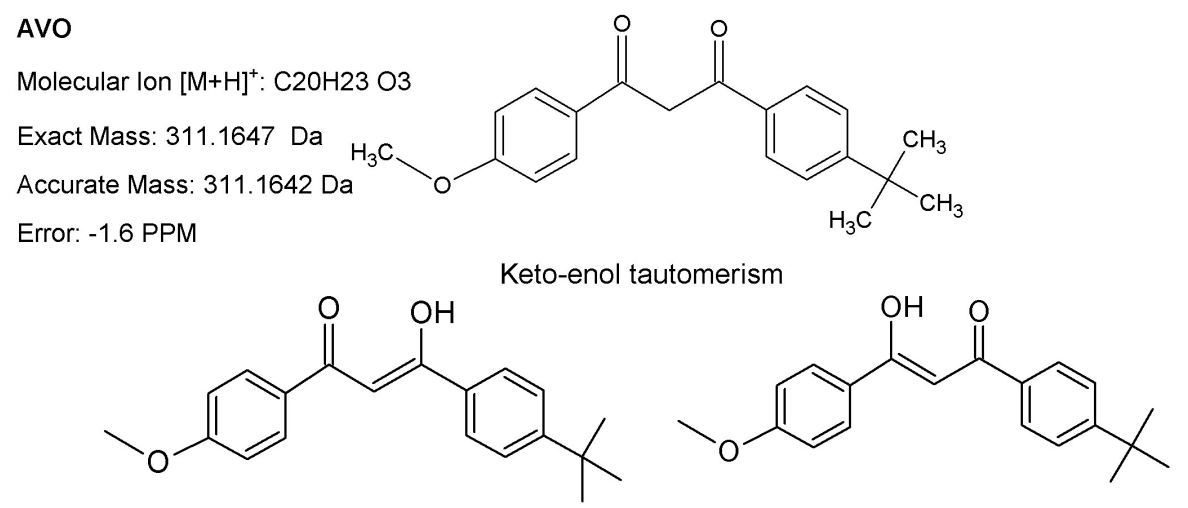

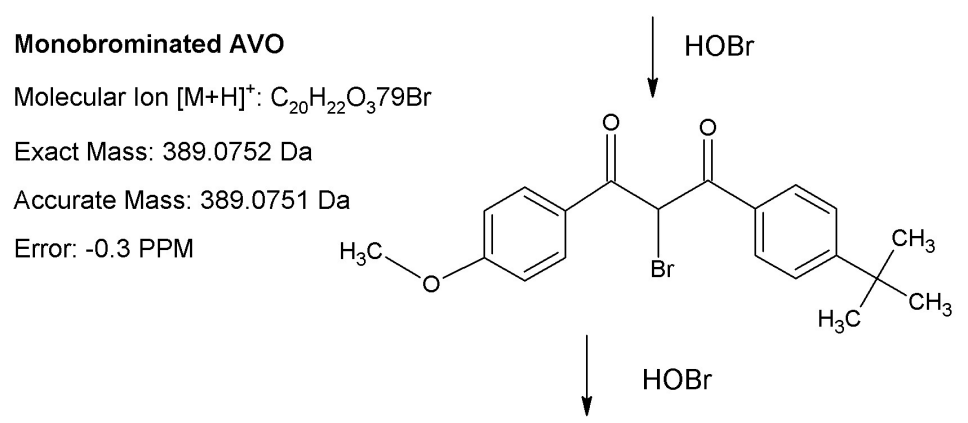

Dibrominated Avobenzone Molecular Ion $[\mathrm{M}+\mathrm{H}]+: \mathrm{C}_{20} \mathrm{H}_{21} \mathrm{O}_{3} 79 \mathrm{Br}_{2}$ Exact Mass: $466.9857 \mathrm{Da}$ Accurate Mass: $466.9851 \mathrm{Da}$ Error: -1.3 PPM<smiles>COc1ccc(C(=O)C(Br)(Br)C(=O)c2ccc(C(C)(C)C)cc2)cc1</smiles>

\section{Bromoform}

Identified by GC-ECD and GC-MS<smiles>BrC(Br)Br</smiles>

The highest levels were detected at the chlorination ratio UV filter:chlorine 1:100 with concentrations reaching $1.9 \mu \mathrm{g} \mathrm{L}^{-1}$ and $4.3 \mu \mathrm{g} \mathrm{L}^{-1}$ for OXY and DIOXY, respectively. The formation of brominated transformation products and brominated DBPs in chlorinated seawater can be explained by the formation of bromine upon the addition of chlorine to seawater in a fast reaction. In these conditions, bromine species become the oxidizing/halogenating species reacting with organic compounds present in seawater. 


\section{SI-6. Mass Spectra of AVO Transformation Products}

\section{MSMS Spectrum of Monobrominated AVO}

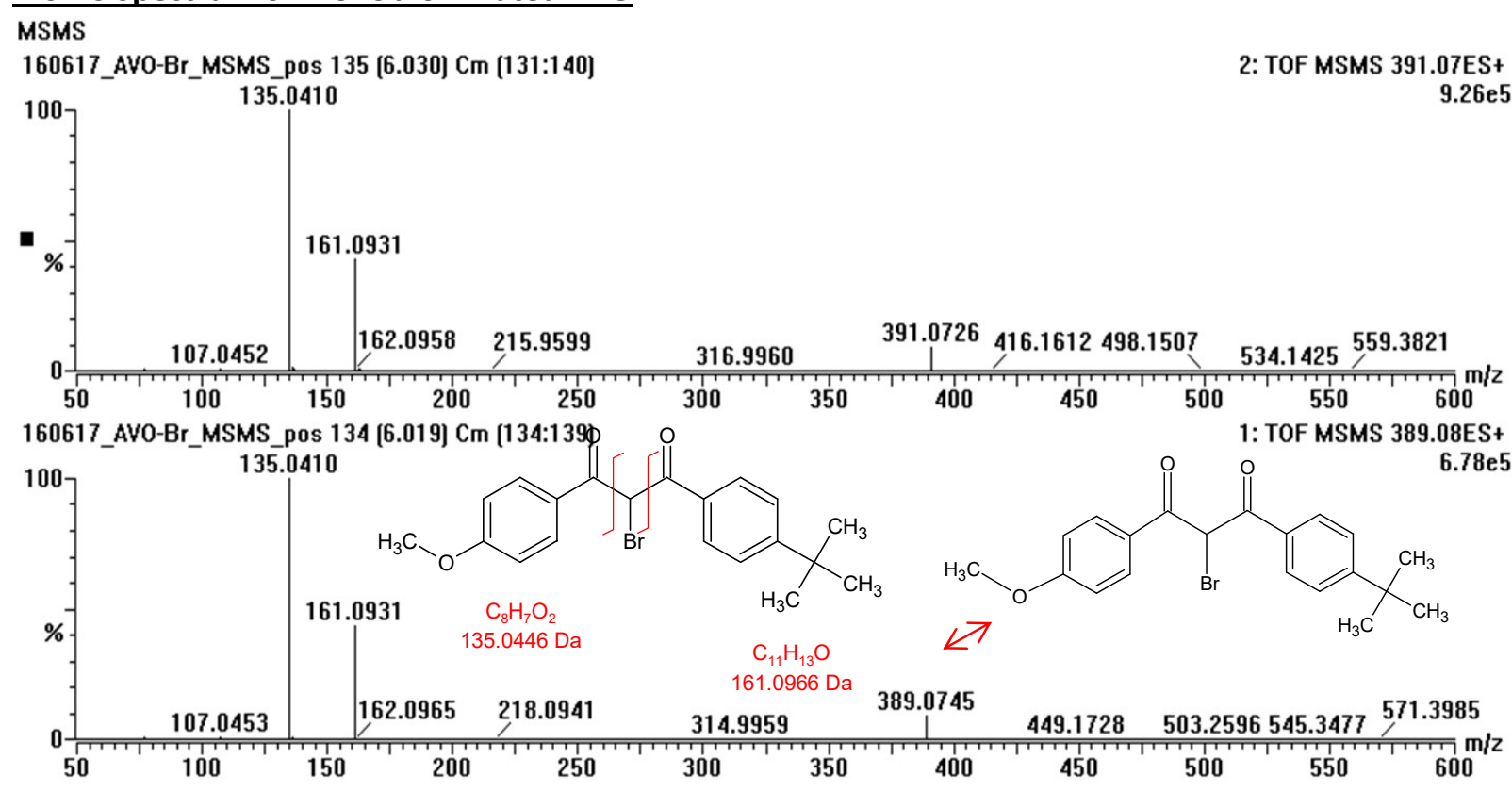

\section{MS Spectrum of Dibrominated AVO}

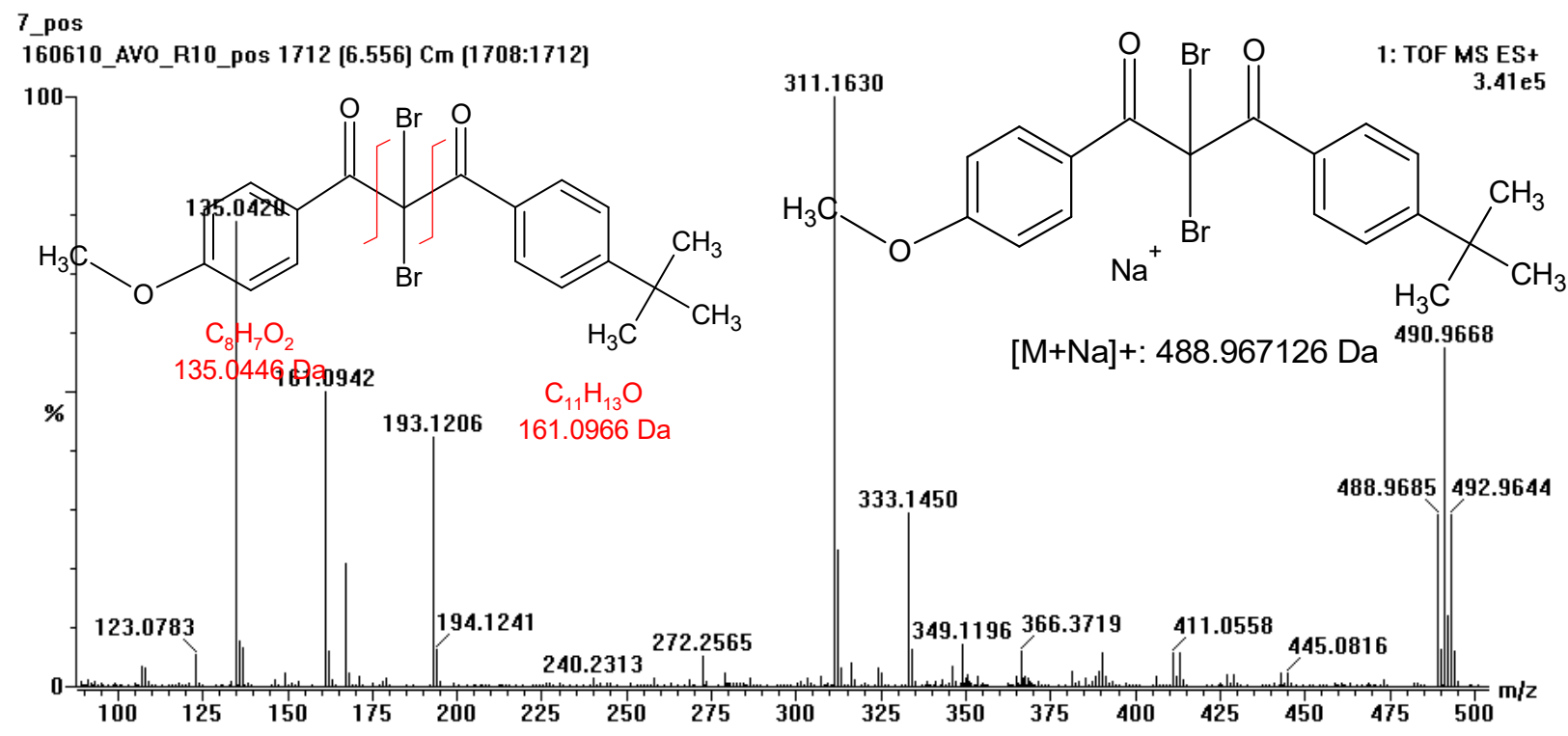

No transformation products were generated from OC in agreement with its observed stability.

These findings provide evidence that some UV filters can act as precursors for the formation of DBPs in swimming pools. The analysis of swimming pool samples allowed the detection of TBMP, bromoform, and bromal hydrate. However, in swimming pool waters complex inputs are continuously introduced by swimmers, so the formation of these detected byproducts cannot be 
attributed exclusively to the UV filters. No other transformation products were detected in swimming pool water samples. The transformation products could be occurring at concentrations lower that the detection limits of our analytical method or could be degraded due to the action of bromine in the pool leading to the formation of final products such as bromoform.

Bromoform Formation Potential. Bromoform was detected as a stable transformation product following the chlorination of DIOXY, OXY, AVO and OMC in seawater. The potential of bromoform formation from UV filters in chlorinated seawater was investigated at the three molar ratios (UV filter:chlorine 1:10, 1:25 and 1:100).
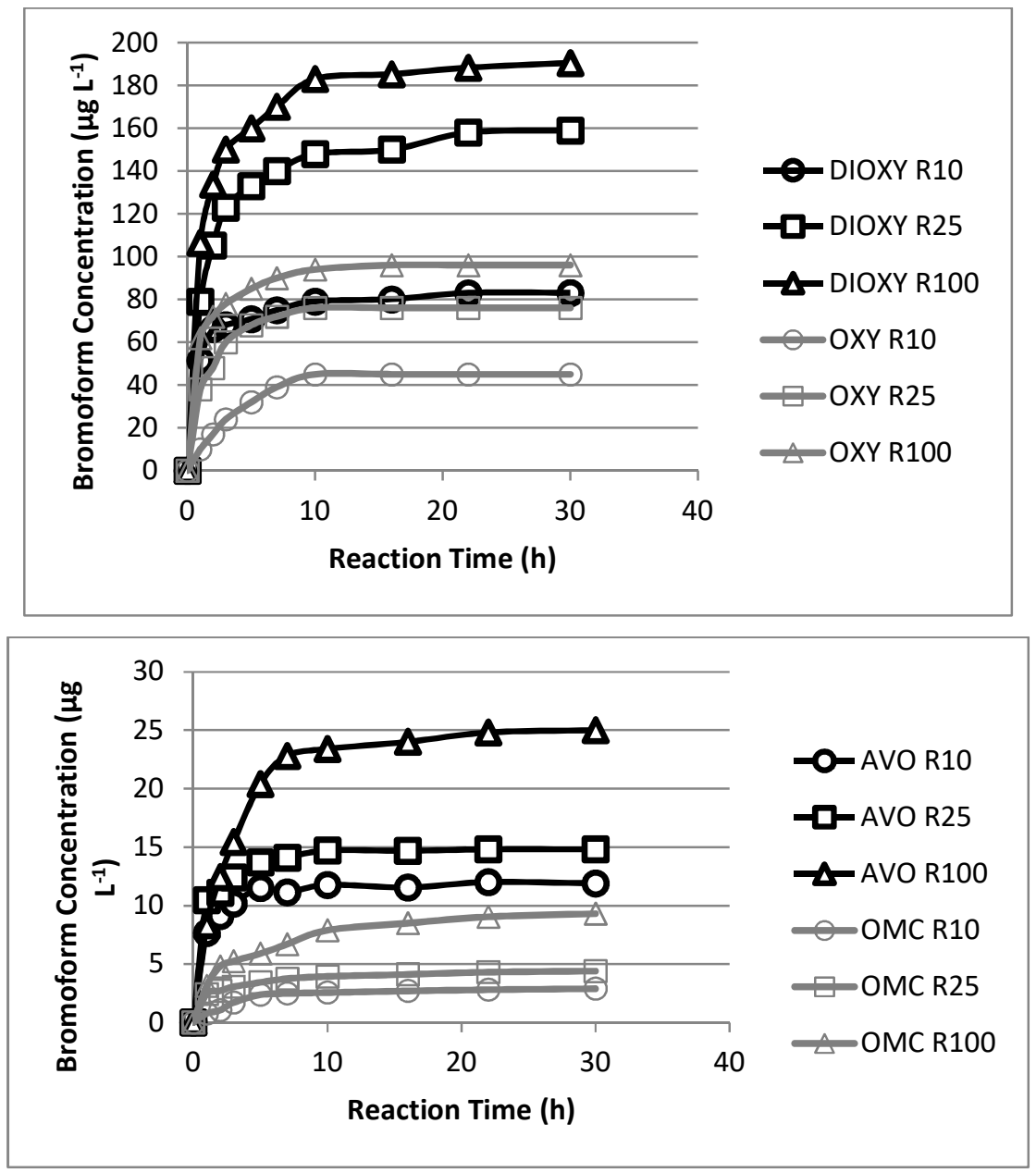

Figure 3. Concentration of bromoform $\left(\mu \mathrm{g} \mathrm{L}^{-1}\right)$ formed from the $\mathrm{UV}$ filters in chlorinated seawater as a function of chlorination reaction time (h). Chlorine was added in excess of 10 folds (R10), 25 folds (R25), and 100 folds (R100) with respect to UV filters.

Figure 3 shows the variation of concentration of bromoform generated by DIOXY, OXY, AVO and OMC as a function of reaction time. The formation of bromoform from DIOXY and OXY 
increased until reaching a plateau $10 \mathrm{~h}$ after the addition of chlorine. This trend in the formation of bromoform is in agreement with the trends of chloroform formation from OXY and DIOXY and from other phenolic compounds. ${ }^{25,53}$ Determining the bromoform formation potential of UV filters allowed distinguishing UV filters that produced relatively high concentrations of bromoform (DIOXY and OXY) and those which produced relatively low concentrations (OMC and AVO). The yields of bromoform formation are described in Table 3 (in mole of bromoform per mole of UV filter).

Table 3. Yields of bromoform produced from the UV filters ( $\mathrm{mol}$ bromoform/mol UV filter) at different chlorination ratios (R10, $\mathrm{R} 25$, and $\mathrm{R} 100)$

\begin{tabular}{cccc}
\hline UV filter & \multicolumn{3}{c}{ Molar yield of bromoform } \\
\hline & R10 & R25 & R100 \\
\cline { 2 - 4 } DIOXY & 0.32 & 0.62 & 0.75 \\
OXY & 0.17 & 0.30 & 0.38 \\
AVO & 0.05 & 0.06 & 0.10 \\
OMC & 0.01 & 0.02 & 0.04 \\
\hline
\end{tabular}

The two benzophenone UV filters OXY and DIOXY had, respectively, a molar yield which ranged from 0.17 to 0.38 and from 0.32 to 0.75 in the presence of excess chlorine (from 10-fold to 100-fold). On the other hand, the molar yield of bromoform formation from AVO and OMC ranged between 0.05 to 0.10 and 0.01 to 0.04 , respectively. The difference in the bromoform formation potential among the UV filters can be related to differences in structures. The higher molar yield of bromoform formation from DIOXY in comparison to OXY can be attributed to the presence of an additional hydroxyl group which activates the aromatic ring. These findings are consistent with previous studies reporting higher haloform yields when additional activating groups are present in aromatic compounds. ${ }^{53} \mathrm{OMC}$ and AVO which lack the phenolic rings and the activation present in the benzophenone UV filters produced lower molar yields of bromoform.

The findings of the present study have environmental and public health implications. The instability of reactive UV filters raises questions about the protection of individuals applying sunscreens and entering chlorinated seawaters from harmful UV solar radiation. These findings suggest the interest of formulating sunscreens containing UV filters that are stable in disinfected pool waters. In addition, the formation of brominated transformation products with unknown 
toxicities and DBPs (bromoform and sometimes bromal hydrate) known to be toxic ${ }^{54,55}$ highlights the importance of reducing the inputs of organic compounds into seawater swimming pools. Furthermore, findings regarding the stability of OC suggest the importance of evaluating the fate and effects of this compound once released into the environment. It also seems important for future investigations to look into the photoreactivity of UV filters. Although the limited findings presented here suggest that bromination constituted the predominant reaction process in chlorinated seawater pools even when the compounds were exposed to solar irradiation, the photoreactivity of UV filters and their fate in pools disinfected with UV treatment requires investigation.

\section{ACKNOWLEDGEMENT}

Tarek Manasfi acknowledges the Doctoral School of "Environmental Sciences" (ED251) at AixMarseille University and the French Ministry of Higher Education and Research for the doctoral scholarship. Authors would like to thank Patrick Höhener for helpful discussions regarding the speciation of bromine and the use of PHREEQC. Authors would like also to thank reviewers for their comments which allowed enhancing the quality of the manuscript.

\section{REFERENCES}

(1) Silvia Díaz-Cruz, M.; Llorca, M.; Barceló, D.; Barceló, D. Organic UV filters and their photodegradates, metabolites and disinfection by-products in the aquatic environment. TrAC Trends Anal. Chem. 2008, 27 (10), 873-887.

(2) Regulation (EC) No 1223/2009 of the European Parliament and of the Council of 30 November 2009 on cosmetic products. Off. J. Eur. Union L. 2009, 342, 59-209

(3) Ramos, S.; Homem, V.; Alves, A.; Santos, L. Advances in analytical methods and occurrence of organic UV-filters in the environment - A review. Sci. Total Environ. 2015, $526,278-311$.

(4) Stokes, R. P.; Diffey, B. L. The water resistance of sunscreen and day-care products. Br. J. Dermatol. 1999, 140 (2), 259-263.

(5) Lambropoulou, D. A.; Giokas, D. L.; Sakkas, V. A.; Albanis, T. A.; Karayannis, M. I. Gas chromatographic determination of 2-hydroxy-4-methoxybenzophenone and octyldimethylp-aminobenzoic acid sunscreen agents in swimming pool and bathing waters by solid- 
phase microextraction. J. Chromatogr. A 2002, 967 (2), 243-253.

(6) Poh Agin, P. Water resistance and extended wear sunscreens. Dermatologic Clinics. 2006, 24(1), 75-79.

(7) Giokas, D. L.; Sakkas, V. A.; Albanis, T. A.; Lampropoulou, D. A. Determination of UVfilter residues in bathing waters by liquid chromatography UV-diode array and gas chromatography-mass spectrometry after micelle mediated extraction-solvent back extraction. J. Chromatogr. A 2005, 1077 (1), 19-27.

(8) Vidal, L.; Chisvert, A.; Canals, A.; Salvador, A. Ionic liquid-based single-drop microextraction followed by liquid chromatography-ultraviolet spectrophotometry detection to determine typical UV filters in surface water samples. Talanta 2010, 81 (1), $549-555$.

(9) Ye, L.; Liu, J.; Yang, X.; Peng, Y.; Xu, L. Orthogonal array design for the optimization of ionic liquid-based dispersive liquid-liquid microextraction of benzophenone-type UV filters. J. Sep. Sci. 2011, 34 (6), 700-706.

(10) Zwiener, C.; Richardson, S. D.; De Marini, D. M.; Grummt, T.; Glauner, T.; Frimmel, F. H. Drowning in disinfection byproducts? Assessing swimming pool water. Environ. Sci. Technol. 2007, 41, 363-372.

(11) Ekowati, Y.; Buttiglieri, G.; Ferrero, G.; Valle-Sistac, J.; Diaz-Cruz, M. S.; Barceló, D.; Petrovic, M.; Villagrasa, M.; Kennedy, M. D.; Rodríguez-Roda, I. Occurrence of pharmaceuticals and UV filters in swimming pools and spas. Environ. Sci. Pollut. Res. 2016, 23 (14), 14431-14441.

(12) Negreira, N.; Canosa, P.; Rodríguez, I.; Ramil, M.; Rubí, E.; Cela, R. Study of some UV filters stability in chlorinated water and identification of halogenated by-products by gas chromatography-mass spectrometry. J. Chromatogr. A 2008, 1178, 206-214.

(13) Balmer, M. E.; Buser, H. R.; Müller, M. D.; Poiger, T. Occurrence of some organic UV filters in wastewater, in surface waters, and in fish from Swiss lakes. Environ. Sci.

Technol. 2005, 39 (4), 953-962.

(14) Gago-Ferrero, P.; Alonso, M. B.; Bertozzi, C. P.; Marigo, J.; Barbosa, L.; Cremer, M.; Secchi, E. R.; Azevedo, A.; Lailson-Brito, J.; Torres, J. P. M.; et al. First determination of UV filters in marine mammals. octocrylene levels in Franciscana dolphins. Environ. Sci. Technol. 2013, 47 (11), 5619-5625. 
(15) Krause, M.; Klit, a.; Blomberg Jensen, M.; Søeborg, T.; Frederiksen, H.; Schlumpf, M.; Lichtensteiger, W.; Skakkebaek, N. E.; Drzewiecki, K. T. Sunscreens: Are they beneficial for health? An overview of endocrine disrupting properties of UV-filters. Int. J. Androl. 2012, 35 (3), 424-436.

(16) Kunz, P. Y.; Fent, K. Multiple hormonal activities of UV filters and comparison of in vivo and in vitro estrogenic activity of ethyl-4-aminobenzoate in fish. Aquat. Toxicol. 2006, 79 (4), 305-324.

(17) Durrer, S.; Ehnes, C.; Fuetsch, M.; Maerkel, K.; Schlumpf, M.; Lichtensteiger, W. Estrogen sensitivity of target genes and expression of nuclear receptor co-regulators in rat prostate after pre- and postnatal exposure to the ultraviolet filter 4-methylbenzylidene camphor. Environ. Health Perspect. 2007, 115 Suppl, 42-50.

(18) Schlumpf, M.; Cotton, B.; Conscience, M.; Haller, V.; Steinmann, B.; Lichtensteiger, W. In vitro and in vivo estrogenicity of UV screens. Environ. Health Perspect. 2001, 109 (3), 239-244.

(19) Klammer, H.; Schlecht, C.; Wuttke, W.; Schmutzler, C.; Gotthardt, I.; Köhrle, J.; Jarry, H. Effects of a 5-day treatment with the UV-filter octyl-methoxycinnamate (OMC) on the function of the hypothalamo-pituitary-thyroid function in rats. Toxicology 2007, $238(2-3)$, 192-199.

(20) Schmutzler, C.; Hamann, I.; Hofmann, P. J.; Kovacs, G.; Stemmler, L.; Mentrup, B.; Schomburg, L.; Ambrugger, P.; Grüters, A.; Seidlova-Wuttke, D.; et al. Endocrine active compounds affect thyrotropin and thyroid hormone levels in serum as well as endpoints of thyroid hormone action in liver, heart and kidney. Toxicology 2004, 205 (1-2), 95-102.

(21) Nakajima, M.; Kawakami, T.; Niino, T.; Takahashi, Y.; Onodera, S. Aquatic Fate of Sunscreen Agents Octyl-4-methoxycinnamate and Octyl-4-dimethylaminobenzoate in Model Swimming Pools and the Mutagenic Assays of Their Chlorination Byproducts. $J$. Heal. Sci. 2009, 55 (3), 363-372.

(22) Richardson, S. D.; Kimura, S. Y. Water Analysis: Emerging Contaminants and Current Issues. Anal. Chem. 2016, 88 (1), 546-582.

(23) Santos, a. J. M.; Miranda, M. S.; Esteves da Silva, J. C. G. The degradation products of UV filters in aqueous and chlorinated aqueous solutions. Water Res. 2012, 46 (10), $3167-$ 3176 . 
(24) Lakind, J. S.; Richardson, S. D.; Blount, B. C. The good, the bad, and the volatile: Can we have both healthy pools and healthy people? Environ. Sci. Technol. 2010, 44 (9), 32053210 .

(25) Duirk, S. E.; Bridenstine, D. R.; Leslie, D. C. Reaction of benzophenone UV filters in the presence of aqueous chlorine: Kinetics and chloroform formation. Water Res. 2013, 47 (2), $579-587$.

(26) Sakkas, V. .; Giokas, D. .; Lambropoulou, D. .; Albanis, T. . Aqueous photolysis of the sunscreen agent octyl-dimethyl-p-aminobenzoic acid. J. Chromatogr. A 2003, 1016 (2), $211-222$.

(27) Heeb, M. B.; Criquet, J.; Zimmermann-Steffens, S. G.; Von Gunten, U. Oxidative treatment of bromide-containing waters: Formation of bromine and its reactions with inorganic and organic compounds - A critical review. Water Res. 2014, 48 (1), 15-42.

(28) Manasfi, T.; Temime-Roussel, B.; Coulomb, B.; Vassalo, L.; Boudenne, J. L. Occurrence of brominated disinfection byproducts in the air and water of chlorinated seawater swimming pools. Int. J. Hyg. Environ. Health 2017, 220 (3), 583-590.

(29) Parinet, J.; Tabaries, S.; Coulomb, B.; Vassalo, L.; Boudenne, J. L. Exposure levels to brominated compounds in seawater swimming pools treated with chlorine. Water Res. 2012, 46 (3), 828-836.

(30) Manasfi, T.; De Méo, M.; Coulomb, B.; Di Giorgio, C.; Boudenne, J. L. Identification of disinfection by-products in freshwater and seawater swimming pools and evaluation of genotoxicity. Environ. Int. 2016, 88, 94-102.

(31) Smith, M. K.; Puczkó, L. Health and wellness tourism; Elsevier/Butterworth-Heinemann, 2009.

(32) Schwartz, M. Encyclopeida of Coastal Science; Springer, 2005.

(33) World Health Organisation. Guidelines for safe recreational water environments: Volume 2. Swimming pools and similar environments. 2006, 2, 146.

(34) Manasfi, T.; Coulomb, B.; Boudenne, J. L. Occurrence, origin, and toxicity of disinfection byproducts in chlorinated swimming pools: An overview. Int. J. Hyg. Environ. Health 2017, 220 (3), 591-603.

(35) Deborde, M.; von Gunten, U. Reactions of chlorine with inorganic and organic compounds during water treatment-Kinetics and mechanisms: A critical review. Water Res. 2008, 42 
(1-2), 13-51.

(36) Gallard, H.; Pellizzari, F.; Croué, J. P.; Legube, B. Rate constants of reactions of bromine with phenols in aqueous solution. Water Res. 2003, 37 (12), 2883-2892.

(37) Abdallah, P.; Deborde, M.; Dossier Berne, F.; Karpel Vel Leitner, N. Kinetics of Chlorination of Benzophenone-3 in the Presence of Bromide and Ammonia. Environ. Sci. Technol. 2015, 49 (24), 14359-14367.

(38) Richardson, S.; Plewa, M.; Wagner, E.; Schoeny, R.; Demarini, D. Occurrence, genotoxicity, and carcinogenicity of regulated and emerging disinfection by-products in drinking water: A review and roadmap for research. Mutat. Res. Mutat. Res. 2007, 636 (13), 178-242.

(39) Yang, Y.; Komaki, Y.; Kimura, S. Y.; Hu, H. Y.; Wagner, E. D.; Mariñas, B. J.; Plewa, M. J. Toxic impact of bromide and iodide on drinking water disinfected with chlorine or chloramines. Environ. Sci. Technol. 2014, 48 (20), 12362-12369.

(40) Plewa, M. J.; Simmons, J. E.; Richardson, S. D.; Wagner, E. D. Mammalian cell cytotoxicity and genotoxicity of the haloacetic acids, a major class of drinking water disinfection by-products. Environ. Mol. Mutagen. 2010, 51 (8-9), 871-878.

(41) Boorman, G. A.; Dellarco, V.; Dunnick, J. K.; Chapin, R. E.; Hunter, S.; Hauchman, F.; Gardner, H.; Cox, M.; Sills ', R. C. Drinking Water Disinfection Byproducs: Review and Approach to Toxicity Evaluation. -Environ Heal. Perspect 1999, 107, 207-217.

(42) Rastogi, S. C. UV filters in sunscreen products - a survey. Contact Dermatitis 2002, 46 (6), $348-351$.

(43) Li, W.; Ma, Y.; Guo, C.; Hu, W.; Liu, K.; Wang, Y.; Zhu, T. Occurrence and behavior of four of the most used sunscreen UV filters in a wastewater reclamation plant. Water Res. 2007, 41 (15), 3506-3512.

(44) Suri, M.; Huld, T.A.; Dunlop, E.D.; Ossenbrick, H.A. Potential of solar electricity generation in the European union member states and candidate countries. Sol. Energy 2007, 81, 1295-1305.

(45) ANSES (French Agency for Food, Environmental and Occupational Health and Safety). Evaluation des risques sanitaires liés aux piscines. Partie 2: Bains à remous, 2013 https://www.anses.fr/fr/system/files/EAUX2007sa0409Ra-2.pdf (Accessed on May 12, 2017). 
(46) Sivey, J. D.; Arey, J. S.; Tentscher, P. R.; Roberts, A. L. Reactivity of BrCl, Br2, BrOCl, $\mathrm{Br} 2 \mathrm{O}$, and $\mathrm{HOBr}$ toward dimethenamid in solutions of bromide + aqueous free chlorine. Environ. Sci. Technol. 2013, 47 (3), 1330-1338.

(47) Sivey, J. D.; Roberts, A. L. Assessing the reactivity of free chlorine constituents $\mathrm{Cl}_{2}, \mathrm{Cl}_{2} \mathrm{O}$, and HOCl toward aromatic ethers. Environ. Sci. Technol. 2012, 46 (4), 2141-2147.

(48) Manasfi, T.; Storck, V.; Ravier, S.; Demelas, C.; Coulomb, B.; Boudenne, J.-L. Degradation Products of Benzophenone-3 in Chlorinated Seawater Swimming Pools. Environ. Sci. Technol. 2015, 49 (15), 9308-9316.

(49) Xiao, M.; Wei, D.; Yin, J.; Wei, G.; Du, Y. Transformation mechanism of benzophenone-4 in free chlorine promoted chlorination disinfection. Water Res. 2013, 47 (16), 6223-6233.

(50) Negreira, N.; Rodríguez, I.; Rodil, R.; Cela, R. Assessment of benzophenone-4 reactivity with free chlorine by liquid chromatography quadrupole time-of-flight mass spectrometry. Anal. Chim. Acta 2012, 743, 101-110.

(51) Acero, J. L.; Piriou, P.; Von Gunten, U. Kinetics and mechanisms of formation of bromophenols during drinking water chlorination: Assessment of taste and odor development. Water Res. 2005, 39 (13), 2979-2993.

(52) Rook, J. Formation of haloforms during chlorination of natural waters. Water Treat. Exam. 1974, 23, 234-243.

(53) Gallard, H.; von Gunten, U. Chlorination of phenols: Kinetics and formation of chloroform. Environ. Sci. Technol. 2002, 36 (5), 884-890.

(54) Richardson, S. D.; Plewa, M. J.; Wagner, E. D.; Schoeny, R.; DeMarini, D. M. Occurrence, genotoxicity, and carcinogenicity of regulated and emerging disinfection byproducts in drinking water: A review and roadmap for research. Mutat. Res. - Rev. Mutat. Res. 2007, 636 (1-3), 178-242.

(55) Manasfi, T.; Méo, M. De; Di, C.; Coulomb, B.; Boudenne, J. Assessing the genotoxicity of two commonly occurring byproducts of water disinfection : Chloral hydrate and bromal hydrate. Mutat. Res. - Genet. Toxicol. Environ. Mutagen. 2017, 813, 37-44. 